\title{
Dysregulation of fibulin-5 and matrix metalloproteases in epithelial ovarian cancer
}

\author{
Dustin B. Manders ${ }^{2}$, Hari Annavarapu Kishore ${ }^{1}$, Adi F. Gazdar ${ }^{3}$, Patrick W. Keller ${ }^{1}$, \\ Jun Tsunezumi ${ }^{4}$, Hiromi Yanagisawa ${ }^{4,5}$, Jayanthi Lea ${ }^{1,2, *}$ and Ruth Ann Word ${ }^{1, *}$ \\ ${ }^{1}$ Department of Obstetrics and Gynecology, Green Center for Reproductive Biology, University of Texas Southwestern Medical \\ Center, Dallas, Texas, USA \\ ${ }^{2}$ Division of Gynecologic Oncology, Department of Obstetrics and Gynecology, University of Texas Southwestern Medical \\ Center, Dallas, Texas, USA \\ ${ }^{3}$ Hamon Center for Therapeutic Oncology, University of Texas Southwestern Medical Center, Dallas, Texas, USA \\ ${ }^{4}$ Department of Molecular Biology, University of Texas Southwestern Medical Center, Dallas, Texas, USA \\ ${ }^{5}$ Current address: Life Science Center, Tsukuba Advanced Research Alliance, University of Tsukuba, Tsukuba, Ibaraki, Japan \\ *Co-senior authors
}

Correspondence to: Jayanthi Lea, email: jayanthi.lea@UTSouthwestern.edu

Ruth Ann Word, email: ruth.word@utsouthwestern.edu

Keywords: extracellular matrix; tumor macrophages; MMP-7; cell adhesion

Received: July 20, 2017 Accepted: February 01, 2018 Epub: February 14, 2018 Published: March 06, 2018

Copyright: Manders et al. This is an open-access article distributed under the terms of the Creative Commons Attribution License 3.0 (CC BY 3.0), which permits unrestricted use, distribution, and reproduction in any medium, provided the original author and source are credited.

\section{ABSTRACT}

Fibulin 5 (FBLN5) is an extracellular matrix glycoprotein that suppresses matrix metalloprotease 9 (MMP-9), angiogenesis and epithelial cell motility. Here, we investigated the regulation and function of FBLN5 in epithelial ovarian cancer (EOC). FBLN5 mRNA was down-regulated 5-fold in EOC relative to benign ovary. Not surprisingly, MMP9 mRNA and enzyme activity were increased significantly, and inversely correlated with FBLN5 gene expression. FBLN5 degradation products of 52.8 and $41.3 \mathrm{kDa}$ were increased substantially in EOC. We identified two candidate proteases (serine elastase and MMP-7, but not MMP-9) that cleave FBLN5. MMP7, but not neutrophil elastase, gene expression was increased dramatically in EOC. Recombinant FBLN5 significantly inhibited adhesion of EOC cells to both laminin and collagen I. Finally, using immunohistochemistry, we found immunoreactive FBLN5 within tumor macrophages throughout human EOC tumors. This work indicates that FBLN5 is degraded in EOC most likely by proteases enriched in macrophages of the tumor microenvironment. Proteolysis of FBLN5 serves as a mechanism to promote cell adhesion and local metastasis of ovarian cancer cells. Promotion of a stable ECM with intact FBLN5 in the tumor matrix may serve as a novel therapeutic adjunct to prevent spread of ovarian cancer.

\section{INTRODUCTION}

Ovarian cancer is the second most common gynecologic malignancy in the US, accounting for approximately 22,000 new cases per year [1]. It is, however, the deadliest gynecologic malignancy, due, in part, to the fact that $75 \%$ of new diagnoses are discovered after the cancer has metastasized [2]. The steps required for the development of metastases represent complex interactions between tumor cells and the host microenvironment that include adhesion of cancer cells to distant sites and infiltration through the extracellular matrix (ECM).

The fibulin family consists of seven ECM proteins characterized by tandem arrays of epidermal growth factor-like domains and a C-terminal fibulin-like module [3]. Altered expression and function of fibulin 5 has been implicated in several human cancers [4-8]. In general, it is considered a suppressor of tumor angiogenesis and a 
potential tumor suppressor, in part through its inhibition of the gelatinases, MMP2 and MMP9 [4, 5, 9]. Fibulin-5 is a 448 amino acid, $66 \mathrm{kDa}$, glycoprotein secreted by smooth muscle cells, fibroblasts and vascular endothelial cells. It has been shown to be prominent in blood vessel walls and in the basement membrane underlying epithelial cells [10]. Functionally, it is a crucial protein in the formation of elastic fibers as it tethers tropoelastin to microfibrils where tropoelastin is cross-linked by lysyl oxidases to form mature elastic fibers [11]. Additionally, it mediates endothelial cell adhesion through its integrin binding domain, and has been shown to be dramatically induced in vascular endothelial and smooth muscle cells in response to injury [12]. On the other hand, FBLN5 antagonizes VEGF signaling resulting in diminution of VEGF-induced proliferation and migration of endothelial cells [13].

Recently, we showed that the RGD domain of FBLN5 was not necessary for FBLN5-mediated elastogenesis but was crucial for inhibition of MMP-9 in the female reproductive tract [14]. The gelatinases, MMP2 and MMP9, are both released in a pro-form that must be converted to the active form to function. Activated gelatinases have the ability to degrade type IV collagen in the basement membrane, an event considered key in tumor cell invasion and metastasis. Studies of human epithelial ovarian cancer (EOC) suggest that overexpression of MMP9 in ovarian cancer stroma is a significant predictor of shortened disease-specific survival [15].

Here, we explored the ECM in human EOC compared with benign ovarian tissue. At the protein level, $66 \mathrm{kDa}$ FBLN5 protein was identified as two additional immunoreactive species, $53 \mathrm{kDa}$ and $41.2 \mathrm{kDa}$ in malignant tissues which were immunoreactive in tumor macrophages, not cancer cells or stroma. Two proteases enriched in macrophages (serine elastase and MMP-7) degraded FBLN5 in vitro. Finally, we showed that FBLN5 degradation may play an important pathologic role in EOC because full length FBLN5 inhibited cancer cell adhesion to select basement membrane proteins laminin and type I collagen. Taken together, the data suggest that FBLN5 is degraded in epithelial ovarian cancer possibly by tumor macrophages that support tumor growth by degrading the matricellular protein thereby leading to increased angiogenesis and upregulation of MMP-9 to further support the invasive phenotype of EOC.

\section{RESULTS}

\section{Fibulin genes are downregulated in ovarian cancer tissues relative to benign ovarian tissue}

To determine if fibulin genes are differentially regulated in ovarian cancer tissue relative to benign ovarian tissue, RNA was extracted from tissue samples and relative mRNA levels of FBLN1, FBLN2, FBLN3, $F B L N 4, F B L N 5$ and $F B L N 7$ were quantified using qPCR
(Figure 1A). FBLN1 (approximately 10-fold), FBLN3 ( 5-fold), FLBN5 ( 5-fold) and FBLN4 ( 2-fold) were downregulated significantly. Although not statistically significant, there was a trend toward downregulation of FBLN2 and FBLN7 in cancer tissue relative to benign. We considered the possibility that matrix proteins may be globally downregulated in EOC simply due to a disproportionate number of ovarian epithelial cells relative to matrix-secreting stromal fibroblasts. Thus, we examined relative mRNA expression of additional ECM proteins: tropoelastin, two collagen and elastin cross-linking enzymes ( $L O X$ and $L O X L 1$ ), two fibrillary collagen genes (COL1A1 and COL3) and procollagen peptidase (bone morphogenic protein-1, BMP1). Tropoelastin mRNA was downregulated 2 -fold in cancer tissue relative to benign (Figure 1B). Expression of the lysyl oxidase family members, $L O X$ and $L O X L 1$, was similar between malignant and benign ovarian tissues. The genes encoding major protein components of type I and type III collagens, COL1A1 and COL3, as well as BMP1 (a metalloprotease that cleaves the c-terminus of procollagens I, II and III) were also similar between the two tissue types (Figure 1B). Taken together, these results suggest that although many genes involved in collagen and elastin synthesis were normally expressed, specific fibulins and tropoelastin are downregulated in ovarian cancer.

Little is known regarding the role of most fibulin family members in EOC. Several lines of evidence indicate that FBLN5 may mediate cell adhesion through its integrin binding domain [3, 16-18] and may modulate cell migration $[7,12,19-22]$. Hence, we focused on FBLN5 and conducted immunoblot analysis of ureaextracted matrix from benign and malignant ovarian tissue. Although not detectable in soluble fractions (not shown), FBLN5 was expressed in the matrix (i.e., urea-extracts) (Figure 1C, 1D). Low levels of immunoreactive FBLN5 were expressed in benign ovarian tissue (Figure 1C). Interestingly, however, immunoreactive proteins of 65 $\mathrm{kDa}$ (full-length FBLN5) were expressed in some, but not all, EOCs. Rather, immunoreactive intensities of 52.8 and $41.2 \mathrm{kDa}$ proteins were increased in EOC relative to benign ovarian tissue. The antibody used in this study was a polyclonal FBLN5 antibody raised against full length rat FBLN5 that recognizes the human protein [23]. Blots developed under identical conditions but without the primary FBLN5 antibody did not reveal bands of 52 or $41 \mathrm{kDa}$. We therefore considered these immunoreactive proteins as degraded FBLN5. The $41 \mathrm{kDa}$ protein was virtually absent in benign ovary but highly expressed in 6 of 11 EOCs (55\%, Figure 1D).

\section{FBLN5 is not expressed in EOC cancer cells in culture}

The finding of increased degradation of FBLN5 in EOC tumors led us to consider use of EOC cell lines 
to investigate regulation of FBLN5. Cytosolic and urea extracts from two commonly used EOC cell lines, HTB77 (SKOV3) and HTB161 (OVCAR3), together with 5 cell lines (Table 1) generated at UTSW [24] were evaluated. FBLN5 was not expressed in any EOC cell line at mRNA or protein level (Figure 2A). Further, TGF $\beta 1$, a known inducer of EMT and FBLN5 gene expression, did not increase FBLN5 in these cells (Figure 2B). Culture media recovered from EOC cell lines treated with vehicle $(\mathrm{Ctl})$ or TGF $\beta 1(5 \mu \mathrm{g} / \mathrm{ml})$ for $48 \mathrm{~h}$ did not proteolyze FBLN5 (Figure 2B), and cancer cell extracts did not metabolize FBLN5 (Figure 2C). These data indicate that (i) FBLN5 gene expression is absent in malignant ovarian epithelial cells but may be expressed in other cell types within the tumor, and (ii) epithelial ovarian cancer cells do not metabolize FBLN5.

\section{MMP9 is upregulated in ovarian cancer whereas TIMP2 is downregulated}

Previously, we showed that FBLN5 downregulated vaginal MMP-9 through its integrin binding domain [14]. This result was in agreement with studies in which fibulin 5 inhibited induction of MMP9 in mouse mammary
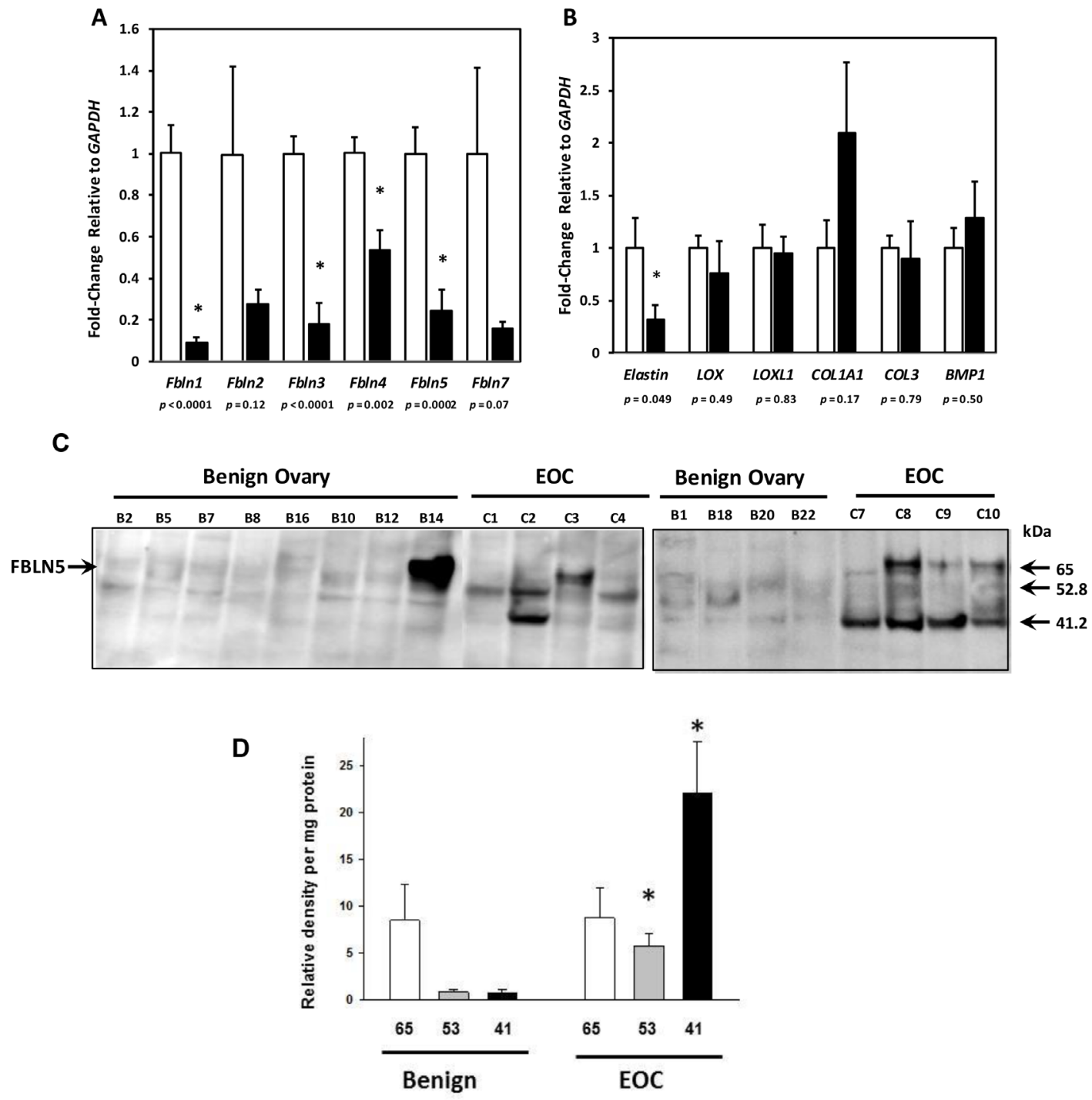

Figure 1: Gene expression of Fibulin family members and matrix proteins in epithelial ovarian cancer (EOC). (A) Relative levels of FBLN mRNA were quantified in ovarian tissue from benign (open bar, $n=12$ ) and EOC (solid bar, serous, $n=8$; mucinous, $n=3$ ). (B) Relative levels of mRNA encoding other matrix proteins (Elastin, tropoelastin; LOX, lysyl oxidase; LOXL1, lysyl oxidase like 1; COL1A1, collagen type Ia; COL3, collagen type 3, and BMP1, bone morphogenic protein-1) in ovarian tissue from benign (open bar, $n=12$ ) and EOC (solid bar, serous, $n=8$; mucinous, $n=3$ ). Data represent mean $\pm \mathrm{SD}$. ${ }^{*} P<0.05$ compared with benign. (C) Fibulin-5 expression in matricellular extracts from benign ovary and EOC. Representative immunoblots of FBLN5 in urea extracts from benign ovary and EOC. Numbers identify each tissue. (D) Relative density units of 65-, 53-, and 41- kDa FBLN5 in benign ovarian tissue $(n=12)$ and EOC $(n=11)$. Data represent mean \pm SEM normalized to total urea-extracted protein quantified on paired Coomassie blots. ${ }^{*} P<0.05$ compared with benign. 
Table 1: Clinical information regarding cell lines used in this study

\begin{tabular}{lcccccc}
\hline Cell line & Ascites $(\mathbf{m l})$ & Site of disease & Stage of disease & Histology & Grade & Race \\
\hline HCC 5011 & 3000 & Ovary & IIIC & Serous & $2-3$ & White \\
HCC 5019 & 1500 & Ovary & IV & Cystadenocarcinoma & 3 & Black \\
HCC 5020 & 1000 & Ovary & IV & Papillary Serous & 3 & Cystadenocarcinoma \\
HCC 5022 & 1500 & Ovary & IIIC & Papillary Serous & 3 & Hispanic \\
HCC 5023 & 2500 & Ovary & & Serous & Adenocarcinoma & 3 \\
\hline
\end{tabular}

A
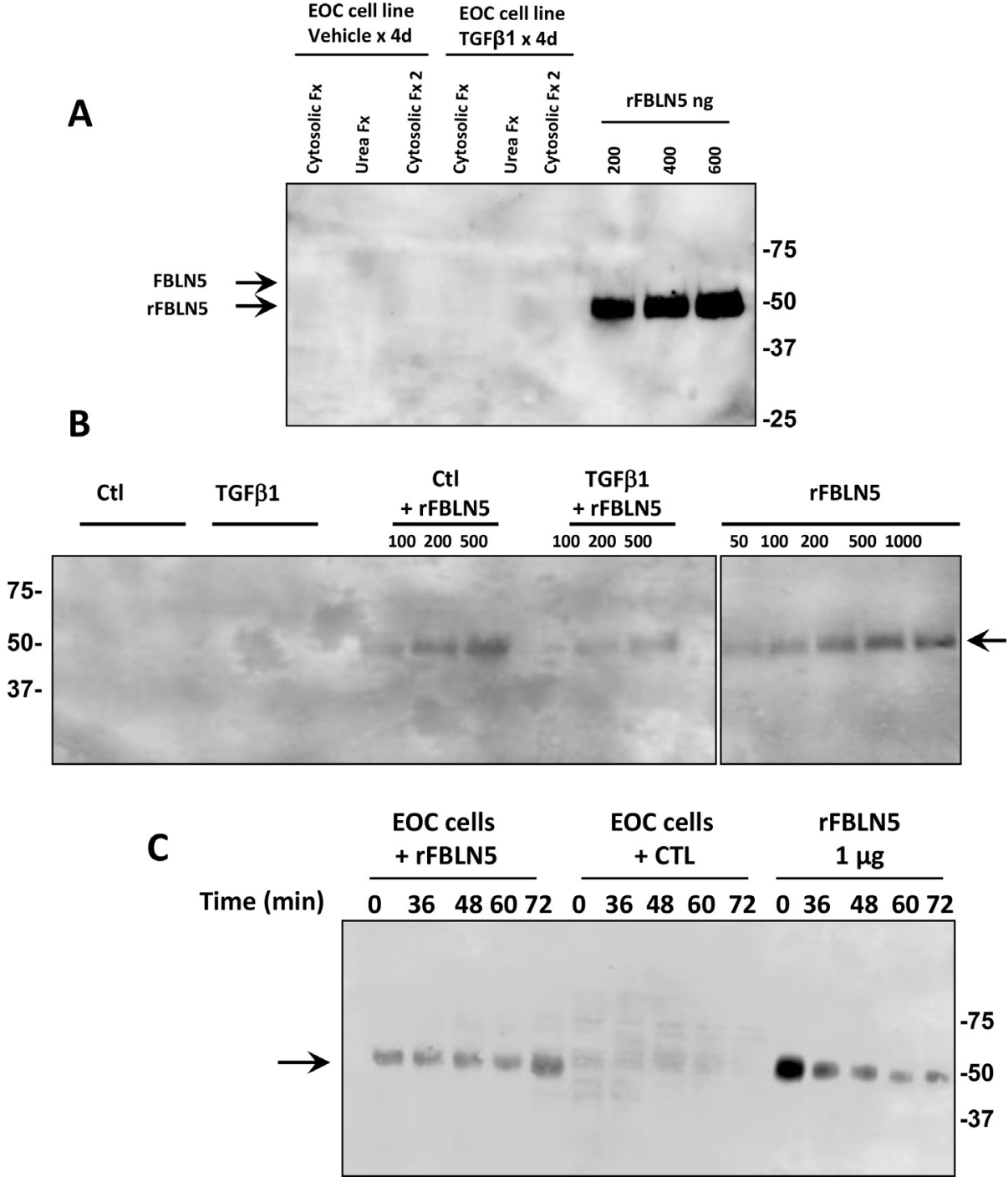

Figure 2: Fibulin-5 is not expressed and not metabolized by EOC cell lines. (A) Immunoblot analysis of FBLN5 in cytosolic and urea extracts from EOC cell line 5020 treated with vehicle or TGF $\beta 1(5 \mu \mathrm{g} / \mathrm{ml})$ for $4 \mathrm{~d}$. Results are representative of 6 cell lines. Cytosolic Fx 2 indicates supernatant of second homogenization of tissue pellet in cytosolic buffer. Arrows denote migration of endogenous glycosylated FBLN5 (65 kDa) (which is absent in these cells) or purified rFBLN-5 (51 kDa). (B) Culture media recovered from EOC cell line 5020 [24] incubated with vehicle (Ctl) or TGF $1(5 \mu \mathrm{g} / \mathrm{ml})$ for $48 \mathrm{~h} \pm$ rFBLN5. rFBLN5 was recovered intact with no proteolytic fragments. (C) EOC cell extracts $(30 \mu \mathrm{g})$ incubated with or without rFBLN5 $(1 \mu \mathrm{g})$ as a function of time. 
adenocarcinoma [4]. Nonetheless, this effect appeared to be tissue-specific because loss of FBLN5 does not lead to upregulation of MMP-9 in the vasculature or lung [14]. To determine, therefore, whether downregulation of FBLN5 in EOC was associated with upregulation of MMP-9, expression of the gelatinases, MMP2 and MMP9, was quantified in benign and malignant ovarian tissue. $M M P 2$ was upregulated 3-fold and MMP-9 6.5-fold in ovarian cancer (Figure 3A). We also examined their inhibitors, TIMP1 and TIMP2. TIMP2, but not TIMP1, gene expression was downregulated 15 -fold in malignant tissues. The results indicate that downregulation of FBLN5 in ovarian cancer was accompanied by dramatic induction of MMP-9 and loss of its inhibitor, TIMP 2 .

As mRNA transcripts do not always reflect in vivo enzyme activity, quantitative gelatin zymography was conducted to analyze the relative activity of MMP9 in benign and malignant ovarian tissues. Although pro- and active forms of MMP9 are difficult to separate, in benign tissues, MMP-9 was either nondetectable or weak whereas both pro- and active MMP-2 were detected. In EOC tissue, MMP-9 was increased significantly (Figure 3B). Using the $95 \%$ confidence interval for benign ovary as the upper limit for normal, MMP-9 was increased in 2 of 12 benign samples, and 7 of 10 cancer samples. MMP9 activity was increased 3- to 9-fold in 5 and 60- to 65-fold in 2 of 10 cancer samples (Figure 3C, $p=0.03$, Fisher's Exact Test).

Next, we assessed MMP-2 and MMP-9 activity in ovarian cancer cell lines (Figure 4). Interestingly, although proMMP-2 was expressed and regulated by TGF $\beta 1$, MMP-9 activity was not expressed in SKOV3 or OVCAR3 and was not induced by TGF $\beta 1$. In contrast, MMP9 activity was readily detectable in 4 of 5 newlyderived lines (passage 22-25) [24], and was induced by TGF $\beta 1$ (e.g., HCC5020, Figure 4).

\section{Candidate proteases to degrade fibulin-5}

We considered possible proteases that degrade FBLN5 and would thereby prevent the tumor suppressive functions of FBLN5. A candidate protease approach was taken. Recombinant human FBLN5 protein $\left(\mathrm{Gln}^{24}-\mathrm{Phe}^{448}\right)$ with a carboxy-terminal poly-histidine tag was incubated with various candidate proteases, and immunoblotting was performed with antibodies to FBLN5 or an anti-His antibody to detect the C-terminal product as indicated in Figures 5-6. Incubation of rFBLN5 (Figure 5A) with MMP9 resulted in no appreciable degradation of rFBLN5 for up to $24 \mathrm{~h}$ (Figure 5B). In contrast, MMP2 resulted in complete degradation of rFBLN5 within $4 \mathrm{~h}$. Degradation products similar to those found in EOC tissue samples, however, were not visualized. Likewise, the serine protease, thrombin, had a modest effect in degrading rFBLN5 by $24 \mathrm{~h}$. As expected, trypsin rapidly and completely degraded rFBLN5. For these four proteases, HIS-tag antibodies identified products identical to those of FBLN5 antibodies with no immunoreactive degradative products (not shown).

Next, we considered the possibility that elastase, a serine protease known to be expressed in pancreas $[25,26]$ and neutrophils [27], may mediate degradation of FBLN5. To interpret the results of this experiment, it should be emphasized that, unlike endogenous FBLN5, rFBLN5 is not glycosylated and the first 24 amino acids are deleted. Therefore rFBLN5 migrates at $50.6 \mathrm{kDa}$ rather than $65-66 \mathrm{kDa}$ on SDS gels. Within one min, rFBLN5 was converted to a $41-43 \mathrm{kDa}$ product and two 11 and 8 $\mathrm{kDa}$ proteins immunoreactive for the HIS tag (Figure $5 \mathrm{C}$ ). Both products decreased as a function of time. The MEROPS database (http://merops.sanger.ac.uk) reveals 20 potential elastase cleavage sites. Our results suggest that elastase proteolyzes rFBLN5 at three sites. The 41 $\mathrm{kDa}$ product indicates a cut site at the amino terminus consistent with the previously described linker region. The smaller products indicate additional cut sites at the C-terminus (Figure 5C).

Finally, MMP7, a matrix metalloproteinase implicated in metastasis of other malignancies [5, 28-30] was considered. Incubation of $200 \mathrm{ng}$ rFBLN5 with MMP7 at a molar ratio of 1:1.8 led to complete
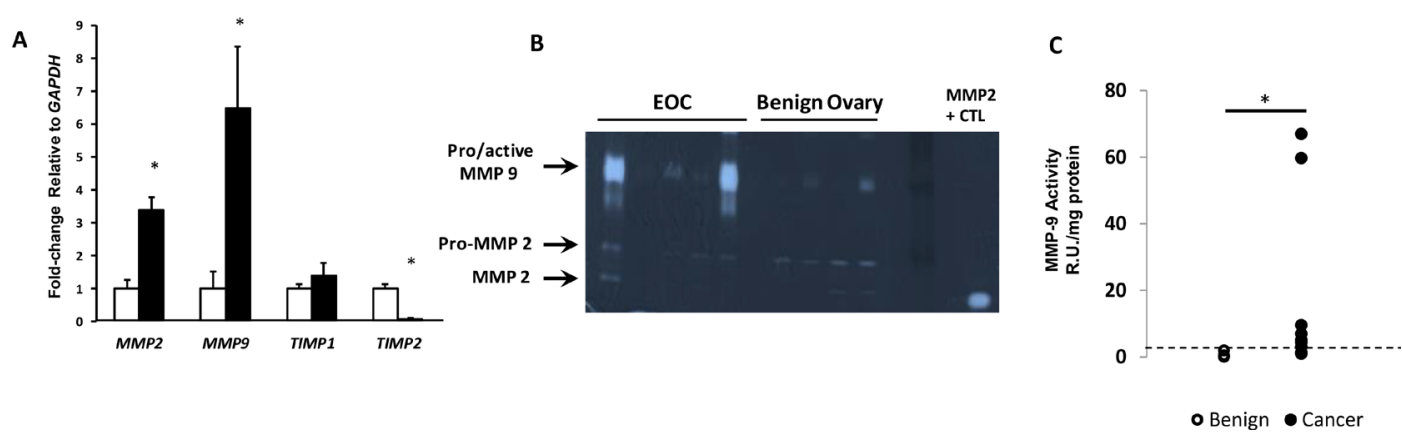

Figure 3: Expression of MMP2 and MMP9 in EOC. (A) Relative levels of $M M P 2, M M P 9$, and MMP inhibitors (TIMP1 and TIMP2) mRNA were quantified in ovarian tissue from benign (open bar, $n=12$ ) and EOC (solid bar, $n=11$ ). Data represent mean $\pm \mathrm{SEM}$. ${ }^{*} P<0.05$ compared with benign. (B) Representative gelatin zymogram of MMP-9 and MMP-2 activity in benign ovary and EOC. (C) Relative units of MMP-9 activity per mg protein extracts from benign $(n=12)$ and EOC $(n=10)$. Dashed line indicates $95 \%$ confidence interval of benign tissues. ${ }^{*} P<0.03$, Fisher's exact. 
degradation of FBLN5 within seconds. Hence, the enzyme was diluted (Figure 6A) demonstrating rapid proteolysis of FBLN5 within 5 min which was rescued by heat inactivation of the enzyme. Degradation products were not visualized with the monoclonal FBLN5 antibody (Figure 6B). The sites of cleavage, therefore, were not clear and investigated further. rFBLN5 tagged at the amino terminus with HA was incubated with MMP-7 and products visualized with HA antibodies and the monoclonal antibody to FBLN5 (Figure 6B). MMP-7 degraded FBLN5, but HA antibodies did not detect the cleaved product. Polyclonal FBLN5 antibodies and silver staining revealed a $37 \mathrm{kDa}$ degraded product (Figure 6C, 6D). Full length and $37 \mathrm{kDa}$ bands were excised and analyzed by mass spectrometry. The $37 \mathrm{kDa}$ protein was identified as amino acid residues $\mathrm{A}^{94}-\mathrm{Phe}^{448}$. Thus, the cleavage site was within the linker region in the insertion site of the first calcium binding EGF-like repeat (Figure 6E). Together with the first 24 amino acids in vivo, the protein would represent a $41 \mathrm{kDa}$ product. The results indicate that MMP-7 also cleaves the C-terminal His tag.

\section{MMP7 expression in malignant and benign ovarian tissues}

Identification of two proteases with unique cut sites for FBLN5 led us to evaluate MMP7 and elastase gene expression in benign and malignant ovarian tissues. Differential expression of $M M P-7$ was highly significant in which $M M P 7$ expression was barely detectable by qPCR in benign ovarian tissues $(\mathrm{Cq}=\sim 30$, Figure 7$)$ but highly expressed in cancer $(\mathrm{Cq}=25$, Figure 7$)$ representing striking increases of 370-fold. Neutrophil elastase, on the other hand, was poorly expressed in both tissue types.

\section{FBLN5 is localized to human tumor macrophages}

Having established increased immunoreactive degradative products of FBLN5 in EOC, next we used immunohistochemistry to localize the protein in these human epithelial ovarian cancers (Figure 8). Large uteroovarian arteries were used as the positive control in which FBLN5 was clearly positive in the extracellular matrix outlining elastic fibers of the vessel wall (Figure 8A). FBLN5 was not observed in blood vessels of ovarian tumors. Rather, the protein was localized to the cytoplasm and granules of tumor macrophages (Figure 8B). Stromal fibroblasts and tumor cells were negative for FBLN5. CD68+ tumor macrophages were distributed throughout the tumor (Figure 8C) and the stromal compartment (Figure 8D), both of which were positive for FBLN5. FBLN5 was absent in macrophages of benign ovary.

\section{Functional significance of FBLN5 in EOC}

Next, we sought to explore the potential function of FBLN5, and more specifically, the physiologic consequence of its degradation in malignant tissues. To answer this question, we turned to cell culture using several ovarian cancer cell lines produced at our institution [24]. We hypothesized that intact FBLN5 may either inhibit tumor cell-derived MMP-9 or inhibit malignant cell adhesion to native ECM components and thereby protect from local spread of the disease. Degradation of FBLN5 would thereby increase MMP-9 protease activity or facilitate ovarian cancer cell adhesion to matrix substrates. Interestingly, although incubation of EOC cells in culture with rFBLN5 did not inhibit tumor cell MMP-9 (not shown), rFBLN5 inhibited adhesion of EOC cells to specific matrix components (Figure 9). Cells from three ovarian cancer cell lines (HCC 5019, 5020, and 5022) were incubated in tissue culture wells pre-coated with a variety of ECM proteins (laminin, collagen type IV, collagen type I and fibronectin) \pm rFBLN5. Bovine serum albumin (BSA) was used as a protein control. Ovarian cancer cells adhered readily to wells coated with fibronectin, regardless of treatment with rFBLN5 (Figure 9). Adherence to other ECM proteins was computed relative
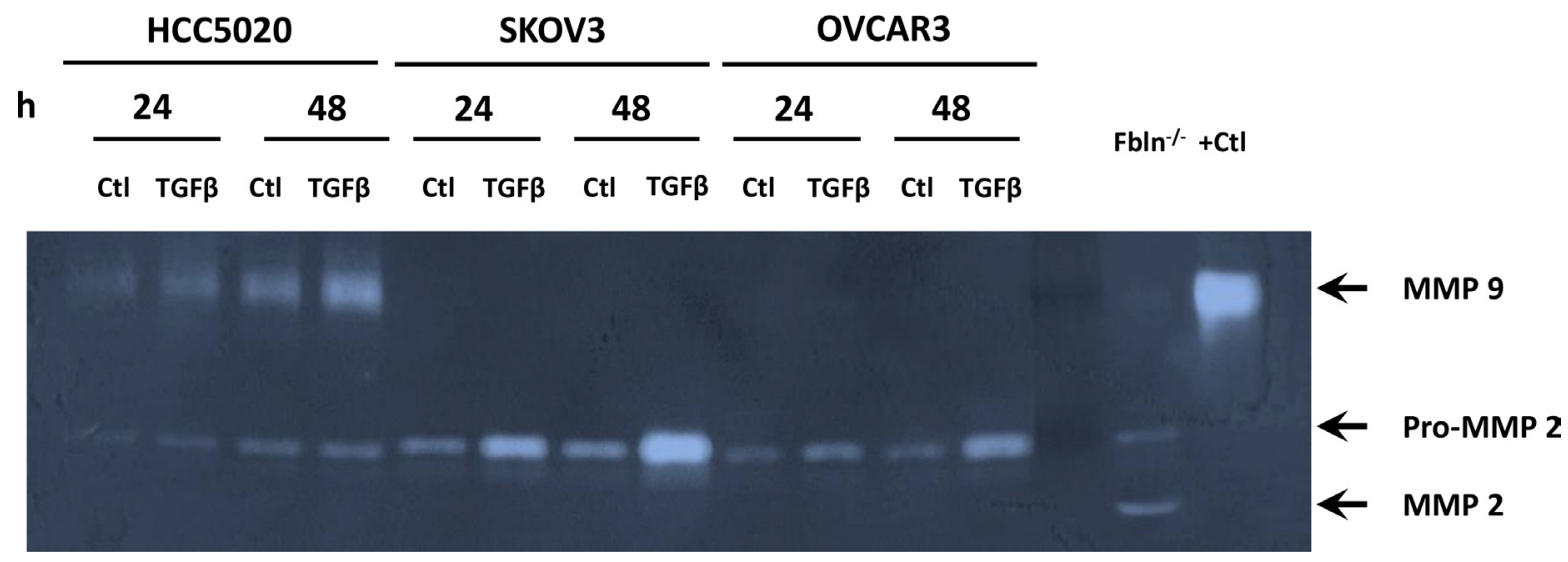

Figure 4: MMP-9 activity is increased in recently discovered ovarian cancer cell lines, but not HTB77 (SKOV3) or HTB161 (OVCAR3). Representative zymogram of media from EOC cell lines cultured with vehicle (Ctl) or TGF $\beta 1$ (5 $\mu \mathrm{g} / \mathrm{ml})$ for $24-48$ h. Positive controls were vaginal tissue from Fbln 5 null mice or purified MMP-9. 
to fibronectin. FBLN5 significantly inhibited EOC cell adhesion to both laminin and collagen I. One physiologic function of FBLN5 is likely to decrease the ability of malignant epithelial ovarian cancer cells to adhere to ECM proteins laminin and type I collagen.

\section{DISCUSSION}

Tumor metastasis beyond the organ of origin is the leading cause of cancer-related mortality. The steps leading to metastasis include (1) local invasion of tumor through a basement membrane, (2) spread of tumor to a distant site (via hematogenous or lymphatic spread, or by direct extension or through peritoneal fluid) and (3) implantation, invasion and proliferation at the distant site. In the present study, we explore the role of the matricellular protein, FBLN5, in the final step of metastasis.

\section{Physiologic significance of reduced expression of FBLN5 in cancer}

FBLN5 has been studied in the context of several epithelial malignancies including breast [4], lung [5], pancreas [6], bladder [7] and prostate [8]. In general, it is thought to represent a tumor suppressing protein, and is often shown to decrease invasion and metastatic colonization of these tumors. Its role in metastatic ovarian cancer is less well elucidated. In agreement with the current study, Heo et al. showed that FBLN5 protein was decreased in EOC relative to 3 benign ovarian cystadenomas and that overexpression of FBLN5 in SKOV3 cells inhibited cell migration and invasion [31]. In our study, we first sought to compare the RNA expression levels of different fibulin proteins in both benign and malignant ovarian tissues. In our samples, Fbln 1, $-3,-4$ and -5 were significantly downregulated in epithelial ovarian cancer (EOC) relative to benign ovarian tissue. This downregulation of FBLN5 in EOC is consistent with downregulation described in other epithelial malignancies [4-8]. Messenger RNA levels of genes encoding many other matrix components were similar between benign and malignant ovarian tissue. Although far from a comprehensive investigation regarding ECM regulation, overall the data suggest that specific fibulins, and not other genes involved in collagen synthesis, are downregulated in EOC.

Two relevant studies demonstrated that reduced levels of FBLN5 result in increased propensity for metastatic spread. Moller, et al., demonstrated that expression of Fbln 5 was decreased in fibroblasts incubated with tumor-conditioned media from mouse mammary adenocarcinoma cell lines compared with fibroblasts cultured in standard media. Additionally, injection of cell lines modified to overexpress Fbln 5 into mice resulted in fewer metastatic deposits than unaltered cancer cell lines [4]. Similarly $\mathrm{Hu}$, et al., reported that FBLN5 protein expression was decreased in human urothelial carcinomas compared with benign bladder tissue. Transfection of FBLN5 in a bladder cancer cell line resulted in decreased
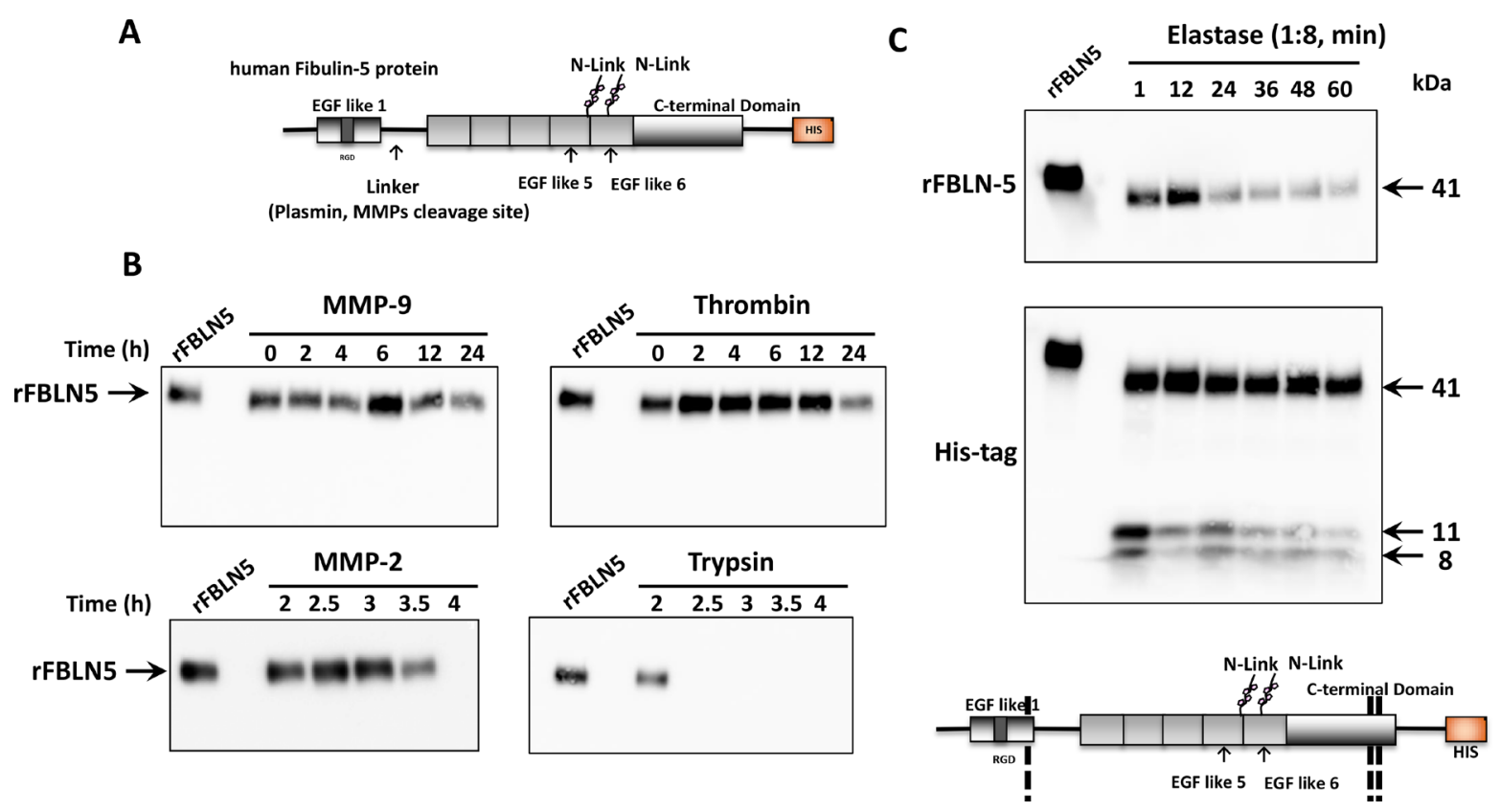

Figure 5: In vitro FBLN5 protease assays. (A) Diagram of recombinant human FBLN5. The amino terminus containing the RGD domain is followed by a linker region, previously described as a cleavage site for plasmin or MMPs. Glycosylated sites are noted and the C-terminal HIS tag is illustrated. (B) Purified MMP-9, MMP-2, thrombin, and trypsin were incubated with rFBLN5 as a function of time. Products were visualized using immunoblot analysis and a monoclonal antibody to human FBLN5. (C) Purified elastase was incubated with rFBLN5 (1:8 molar ratio) as a function of time. Thereafter, products were visualized using immunoblot analysis and antibodies to FBLN5 (upper blot) or the HIS tag (lower blot). Approximate cleavage sites are noted in the diagram. 
growth rates, cell invasion and cell migration compared with non-transfected and empty vector-transfected controls [7]. Interestingly, transfection of Fbln5 into our EOC cell lines resulted in cell death even at low levels of transfection reagents (data not shown). These results, taken together with several lines of investigation [4, 7], led us to suggest that decreased Fbln 5 in EOC may result in increased invasiveness and metastasis.

\section{Relationship between MMPs and FBLN5}

In several studies, expression of FBLN5 was related to expression of the gelatinases, MMP2 and MMP9. In experiments by Moller [4], conditioned media from mammary adenocarcinoma cell lines significantly increased expression of MMP9 in fibroblasts. These results were countered by overexpression of FBLN5. Additionally, by culturing their cells with an MMP2/9 selective inhibitor, they showed inability of these cells to invade an extracellular matrix model [4]. Our previous work extended these observations. Using a knock-in model of FBLN5 in which the integrin binding RGD domain was mutated to RGE, we demonstrated that FBLN5-mediated suppression of MMP-9 was cell-specific and mediated through its RGD domain [14]. It was not surprising, therefore, that FBLN5 suppresses MMP-9 in some cells, but not in our malignant EOC cell lines. Nonetheless, this result does not rule out the possibility that FBLN5 may suppress MMP-9 generated in tumor stroma or macrophages. Huang, et al., reported that host-derived MMP9 expression, likely from tumor-infiltrating macrophages, played a critical role in angiogenesis and progressive growth of human ovarian tumors in mice [32]. In contrast, Shibata, et al., concluded that host peritoneal/mesothelial cells secrete an unidentified factor that induces MMP9 in human EOC cell lines [33]. In our studies, degradation of FBLN5 appeared to be independent of tumor cells in culture or tissue extracts. It is possible that tumor macrophages, or peritoneal cells, may mediate FBLN5 degradation in EOC tumors. Further, the unidentified factor described by Shibata et al. may represent a protease that degrades FBLN5 in EOC.

The clinical implications of increased MMP9 have been independently demonstrated by Kamat and Sillanpaa [15]. Both showed that stromal expression of MMP9 resulted in shortened disease-specific survival in patients with EOC [15, 34]. Finally, Yang, et al., demonstrated improved survival in a murine orthotopic model of disseminated ovarian cancer with treatment with a conditionally replicating adenovirus expressing TIMP2, an inhibitor of MMP9 [35]. Our findings in which MMP9 was increased 6.5-fold and TIMP-2 downregulated 15-fold in EOC are in agreement with these studies.

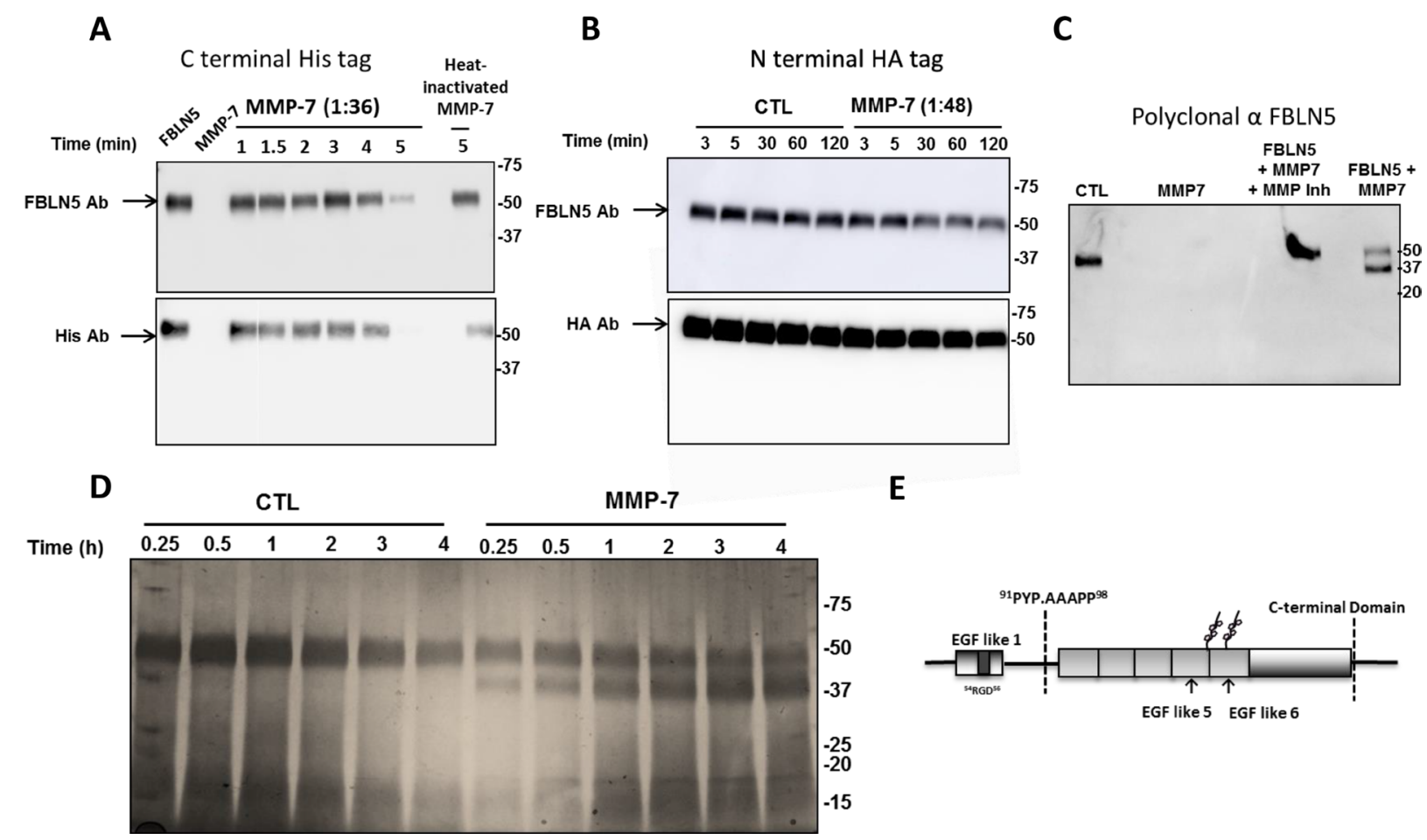

Figure 6: Effect of MMP-7 on degradation of FBLN5 in vitro. (A) Purified MMP-7 (1:36 molar ratio) was incubated with rFBLN5 as a function of time. Thereafter, products were visualized using immunoblot analysis and antibodies to FBLN5 or HIS tag. (B) Diluted MMP-7 was incubated as a function of time (in minutes) with rFBLN5 with an amino terminus HA tag. (C) FBLN5 (200 ng), MMP-7 (1:36), or FBLN5+MMP7 \pm actinonin (a general MMP inhibitor) was incubated at $37^{\circ} \mathrm{C}$ for 5 min. Thereafter, the proteins were transferred an incubated with a polyclonal antibody to FBLN5. (D) Silver stain of FBLN5 incubated for 4 min with or without MMP-7. (E) Diagramatic sites of cleavage of MMP-7. Sequence of cut site is shown. 


\section{Degradation of FBLN5}

Our results indicate that Fbln5 mRNA is downregulated in EOCs. Paradoxically, immunoreactive proteins to FBL5 antibodies were increased in EOC relative to benign ovarian tissues. We concluded that the immunoreactive proteins represented FBLN5 degradation proteins because all products were of decreased molecular size and were absent in tissue extracts incubated without FBLN5 antibodies (negative control blots). The mechanisms of downregulated Fbln 5 mRNA are not known but may represent cellular responses to FBLN5 fragments or as part of an abnormal transcriptome response. Nevertheless, downregulation of gene expression, together with protein degradation, favors loss of FBLN5 in EOC tumors.

Degradation of FBLN5 has been described in other pathological conditions. For example, Vierkotten, et al., reported that degradation of FBLN5 led to fragmentation of Bruch's membrane and increased risk of age-related macular degeneration [36]. Hirai, et al., showed that increased proteolytic cleavage in its $\mathrm{N}$-terminal linker region with age, and that the truncated version is unable to promote elastogenesis [11]. Djokic et al. described proteolytic cleavage of fibulin-5 in the N-terminal linker region by a number of MMPs including MMP-2, -7 , and -12 in vitro [37]. Interestingly, among fibulin proteases, MMP-7 was particularly potent [37].

\section{FBLN5 and EOC cell adhesion}

Given its role in cell adhesion and metastasis in other cancers, we sought to understand the role of FBLN5 in EOCs using cell adhesion assays and three ovarian cancer cell lines developed at our institution. FBLN5 significantly decreased adhesion of the three cell lines tested to the ECM proteins laminin and collagen I. It should be emphasized that recombinant FBLN5 $\mathrm{Gln}^{24}$ $\mathrm{Phe}^{448}$ was used for these assays which may not be folded physiologically due to lack of glycosylation. Nevertheless, this in vitro experiment suggests that FBLN5 may protect EOC metastasis by preventing cancer cell adhesion to specific ECM proteins.

The mechanisms by which FBLN5 prevented adhesion to collagen and laminin are not known. FBLN5 is known to bind to several cell types. For example fibulin-5 binds to integrins $\alpha 9 \beta 1, \alpha v \beta 3$, and $\alpha v \beta 5$ in CHO cells [38] and to $\alpha 5 \beta 1$ and $\alpha 4 \beta 1$ in aortic smooth muscle cells [16]. In general, $\beta 1, \beta 3$ and $\beta 5$ subunits are highly expressed in ovarian cancer cell lines [39]) with $\beta 6$ subunit present at varying levels. $\alpha v \beta 6$ integrin is also highly expressed in EOC cell lines [40]. Since integrins $\alpha 1 \beta 1, \alpha 2 \beta 1, \alpha 10 \beta 1$, and $\alpha 11 \beta 1$ represent the predominant integrin receptors for collagen, fibulin-5 may not bind collagen directly. Potential interactions of fibulin-5 with collagen receptors discoid domain receptor (DDR) 1 and 2 have not been investigated although DDR1 is highly expressed in EOC [41, 42]. As for laminin, it is possible that fibulin-5 may compete with laminin receptors $(\alpha v \beta 3, \alpha v \beta 5, \alpha 9 \beta 1)$. The finding that fibulin-5 inhibited adhesion of EOC cells to both laminin and collagen I might suggest the presence of other glycoproteins that have been suggested to enhance interactions between cell-matrix molecules by cross-linking a number of molecules including integrins, laminin, and collagens.

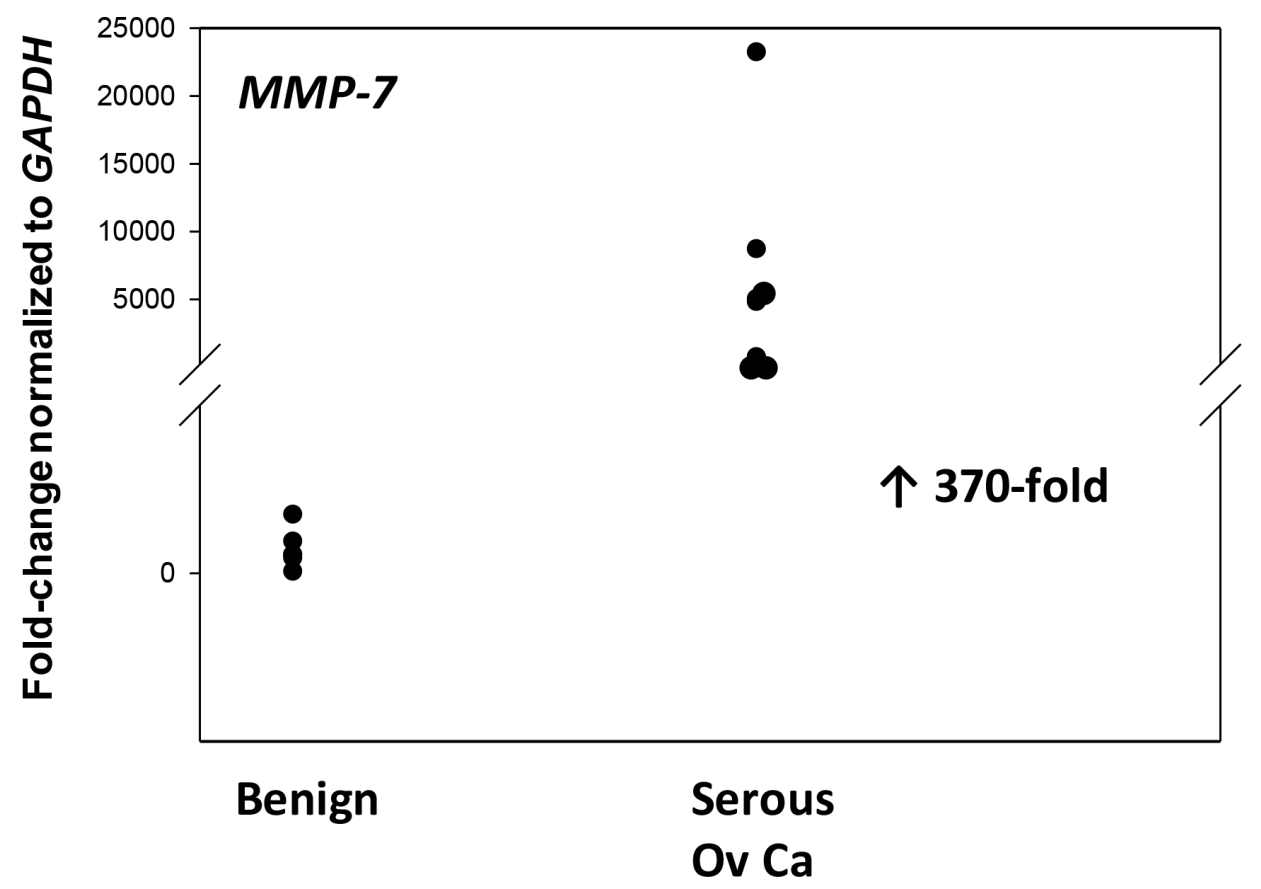

Figure 7: MMP-7 gene expression is upregulated in advanced serous EOC. Relative levels of MMP-7 mRNA were quantified in ovarian tissue from benign $(n=12)$ and EOC (serous, $n=8) . P<0.001$. 


\section{Candidate proteases}

We and others [11] have sought to understand proteolytic degradation of FBLN5. Previously, we identified an unknown serine protease increased in tissues from subjects with pelvic organ prolapse and a candidate serine protease that degraded FBLN5 in vitro [43]. Likewise, degradation of endogenous FBLN5 was shown to be increased in connective tissues of aging mice and mediated by an unknown serine protease [11]. Using in vitro assays
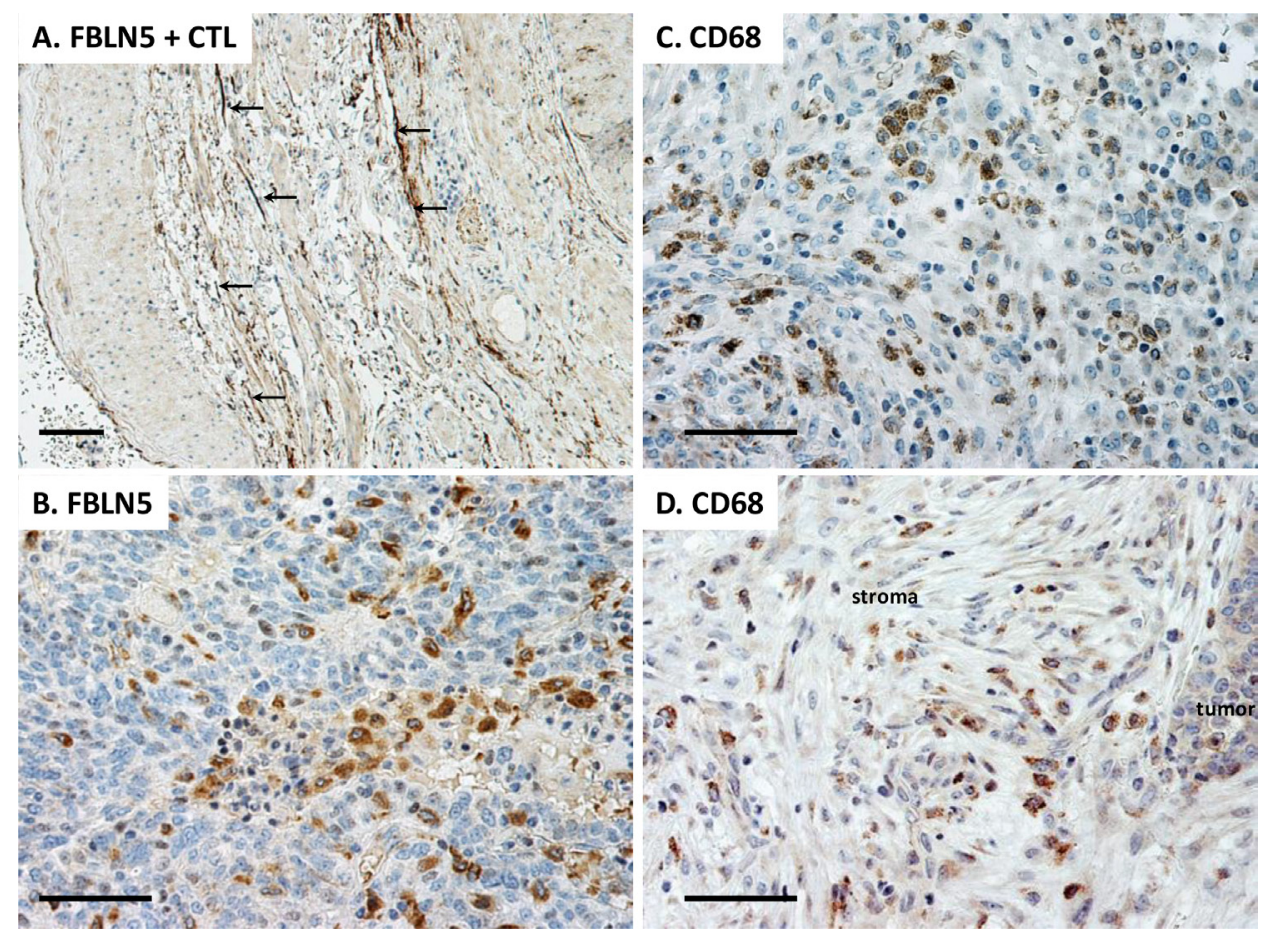

Figure 8: Immunolocalization of FBLN5 in EOC. Sections were stained with either FBLN5 antibodies $(\mathbf{A}, \mathbf{B})$ or the macrophage marker CD68 (C, D). The positive control is shown as large arteries from the utero-ovarian vessels. FBLN5 (arrows) is localized to elastic fibers of blood vessels. Tumor macrophages, but not malignant epithelial cells, are positive for FBLN5 (B). Macrophages are highlighted by CD68 staining in EOC (C) and stroma of the EOC (D). Images represent reproducible and consistent results from 3 high grade serous tumors. Immunostaining without primary antibody is negative. $\mathrm{Bar}=50 \mu \mathrm{m}$.

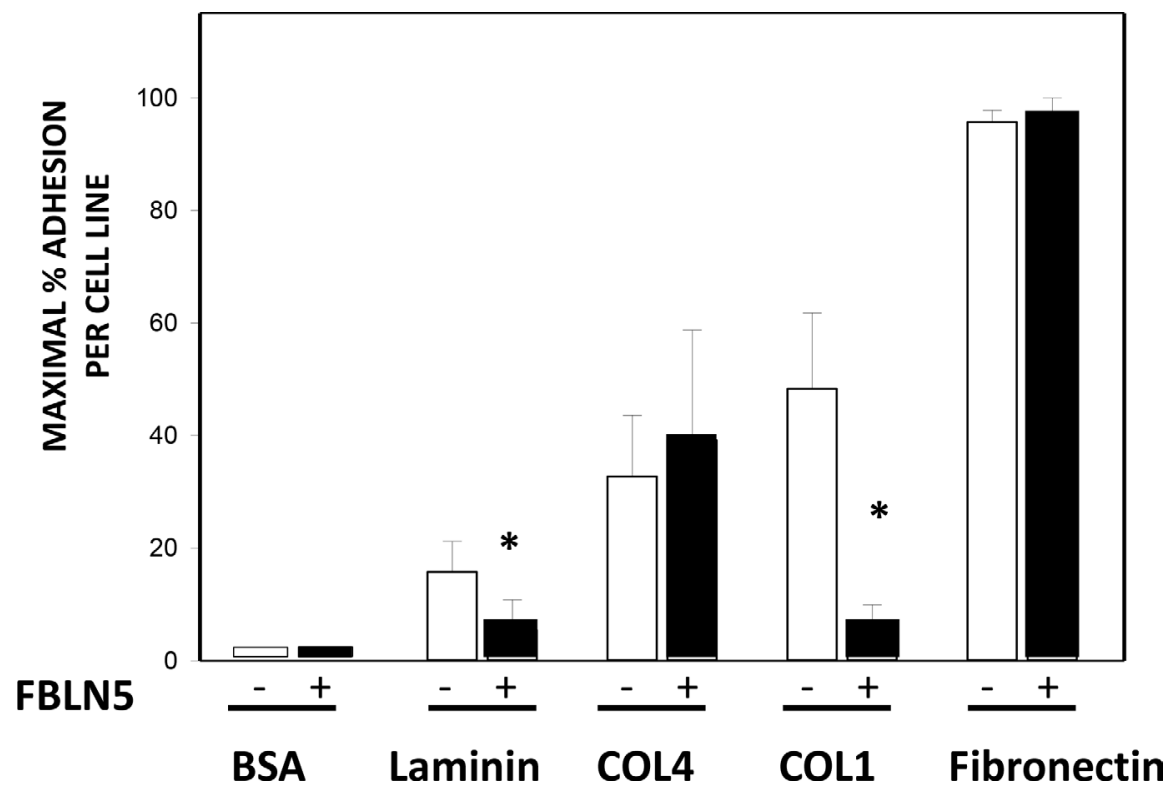

Figure 9: Effect of FBLN5 on EOC cell adhesion. Cell adhesion assays were conducted with 3 different EOC cell lines (HCC 5019,5020 , and 5022) on various substrates. Adhesion to fibronectin was considered maximal and maximal adhesion for each cell line was considered $100 \%$. Bars represent mean \pm SEM of 3 cell lines analyzed in triplicate. ${ }^{*} P<0.05$ compared with matrix without FBLN5. 
and a candidate protease approach, we discovered two potential candidates that may degrade FBLN5 in EOC. First, a serine protease (purified porcine pancreatic elastase) degraded recombinant human FBLN5 within one minute to a $43 \mathrm{kDa}$ product, similar size as the degraded fragment in EOC tumors. MMP7, however, was more potent and generated a degradation band of the expected size. By mass spectrometry, the cleavage site was identified in the linker region. Interestingly, a cleavage site similar to this was noted during purification of fibulin-5 [36] suggesting this site may be particularly vulnerable to proteolysis. Sequence specificity studies of several MMPs indicate that the P1' site plays a critical role with little protease activity among peptides with a charged group or proline at P1'. Alanine at P1' is most favored by MMP-1, -3, -7, and MMP-8 and compatible with FBLN5 $\mathrm{A}^{94}$ identified in the current study for MMP-7.

It is well-appreciated that tumor macrophages and MMPs contribute to progression of a number of malignancies [44], and much of their activities relate to remodeling of the ECM [45]. MMP7 has been shown to be overexpressed in human EOC [29, 46, 47]. MMP7 degrades many ECM proteins including collagens, proteoglycans, laminin, fibronectin, elastin and casein [28]. Additionally, MMP7 is able to convert proMMP2 to active MMP2 and proMMP9 to active MMP9 [29] thereby facilitating macrophage-tumor-stromal cell cross-talk. Overexpression of MMP7 has been shown to increase the invasiveness of several malignancies, including those of the colon and prostate [30]. Incubation of macrophages with malignant breast cancer cell lines, but not benign mammary epithelial cells, results in upregulation of macrophage MMP-7 [48]. We suggest that ovarian cancer cells stimulate MMP7 production from tumor macrophages that readily degrade fibulin-5 thereby facilitating tumor progression and invasion. This idea is supported by the findings that reduced expression of FBLN5 correlates with poor prognostic features in hepatocellular carcinoma [21], and FBLN5 negatively regulates MMP-7 in these cells. FBLN5 may thereby exert its anti-metastatic function, in part, by down-regulating expression of MMP-7. Yue, et al. showed that FBLN5 suppressed lung cancer invasion by inhibition of MMP7 expression [5]. FBLN5 was silenced by promoter hypermethylation, and this resulted in activation of MMP7 and increased tumor invasion. Also, Wang, et al., suggested that MMP7, which was stimulated in EOC by VEGF and IL-8, activated proMMP2 and proMMP9 which was associated with increased invasion of EOC cells [29].

In summary, we found dramatic upregulation of MMP7 and FBLN5 degradative products in tumor macrophages of EOC. FBLN5 was shown to inhibit adhesion of EOC to matrix components. Together, the data provide insights regarding macrophage-induced regulation of the matrix microenvironment of EOCs that likely lead to increased adhesiveness of EOC metastatic spread.

\section{MATERIALS AND METHODS}

\section{Human ovarian tissues}

Benign human ovarian tissues were obtained from pre-menopausal women undergoing oophorectomy for reasons other than malignancy $n=12$. Malignant ovarian tissue was obtained from patients undergoing cytoreductive surgery for metastatic epithelial ovarian cancer $(n=11)$. Biopsies were obtained primarily from metastatic sites. Tissues were snap frozen in liquid nitrogen, and stored at $-80^{\circ} \mathrm{C}$ until use. The protocol for obtaining these tissues was approved by the Institutional Review Board of the University of Texas Southwestern Medical Center.

\section{RNA extraction}

RNA was extracted as previously described [49]. Briefly, tissues were pulverized in liquid nitrogen and homogenized in RNA Stat-60 (TelTest Inc., Friendswood, TX, USA). Total RNA was then extracted according to the manufacturer's protocol, using chloroform (C2432, Sigma, St. Louis, MO, USA), isopropanol (I9516, Sigma, St. Louis, MO, USA), and ethyl alcohol (E190, PharmacoAaper, Brookfield, CT, USA).

\section{cDNA synthesis}

Reverse transcription was performed as previously described [50]. Reactions were conducted with $2 \mu \mathrm{g}$ total RNA in a reaction volume of $20 \mu \mathrm{l}$. Each reaction contained $10 \mathrm{mM}$ dithiothreitol, $0.5 \mathrm{mM}$ deoxynucleotide triphosphates, $0.015 \mu \mathrm{g} / \mathrm{ml}$ random primers, $40 \mathrm{U}$ RNase inhibitor (10777-019; Invitrogen, Carlsbad, CA, USA), and $200 \mathrm{U}$ reverse transcriptase (18064-014; Invitrogen). Reaction conditions were $10 \mathrm{~min}$ at $23^{\circ} \mathrm{C}, 60 \mathrm{~min}$ at $50^{\circ}$ $\mathrm{C}$, and $15 \mathrm{~min}$ at $70^{\circ} \mathrm{C}$.

\section{Quantitative real-time PCR}

PCR reactions were performed in the manner previously described [51]. Reactions were carried out on an ABI Prism 7000 sequence-detection system (Applied Biosystems). The reverse transcription product from 50 ng RNA was used as the template, and reaction volumes (30 $\mu \mathrm{l})$ contained Master Mix (Applied Biosystems). Primer concentrations were $900 \mathrm{nM}$. Cycling conditions were $2 \mathrm{~min}$ at $50^{\circ} \mathrm{C}$, followed by $10 \mathrm{~min}$ at $95^{\circ} \mathrm{C}$, then 40 cycles of $15 \mathrm{sec}$ at $95^{\circ} \mathrm{C}$ and $1 \mathrm{~min}$ at $60^{\circ} \mathrm{C}$. SYBR Green was used for amplicon detection. Gene expression was normalized to expression of the housekeeping gene, GAPDH, which was invariant among samples. A preprogrammed dissociation protocol was used after amplification to ensure that all the samples exhibited a 
Table 2: Primers used in this study

\begin{tabular}{|c|c|c|c|c|}
\hline Gene & Accession \# & Forward primer & Reverse primer & Probe \\
\hline $\mathrm{h}$ Elastin & BC 065566 & $\begin{array}{l}\text { TGCAGCCTATAAAGCTGCTAAGG } \\
\qquad(330-352)\end{array}$ & $\begin{array}{c}\text { GGCACTTTCCCAGGCTTCA } \\
(455-437)\end{array}$ & - \\
\hline $\mathrm{h} L O X$ & AF 039291 & $\begin{array}{l}\text { GCGGCGGAGGAAAACTGT } \\
(964-981)\end{array}$ & $\begin{array}{l}\text { AGCAGCACCCTGTGATCATAATC } \\
(1037-1015)\end{array}$ & - \\
\hline $\mathrm{h} L O X L 1$ & BC 068542 & $\begin{array}{l}\text { GACTGCCAGTGGATCGACATAA } \\
(1875-1896)\end{array}$ & $\begin{array}{l}\text { CTCCAAAACAATATACTTTGGGTTCA } \\
(1961-1936)\end{array}$ & - \\
\hline $\mathrm{h} M M P 2$ & BC 002576 & $\begin{array}{l}\text { TTGATGGCATCGCTCAGATC } \\
\qquad(1690-1709)\end{array}$ & $\begin{array}{l}\text { TGTCACGTGGCGTCACAGT } \\
(1770-1752)\end{array}$ & - \\
\hline $\mathrm{h} M M P 9$ & BC 006093 & $\begin{array}{l}\text { GAACTTTGACAGCGACAAGAAGTG } \\
(1136-1159)\end{array}$ & $\begin{array}{l}\text { GCCGCCACGAGGAACA } \\
(1204-1189)\end{array}$ & - \\
\hline $\mathrm{h} C O L 1 A 1$ & NM 000088 & $\begin{array}{l}\text { ACGAAGACATCCCACCAATCA } \\
(221-241)\end{array}$ & $\begin{array}{l}\text { CGTTGTCGCAGACGCAGAT } \\
(322-304)\end{array}$ & - \\
\hline $\mathrm{h} C O L 3 A 1$ & NM 000090 & $\begin{array}{l}\text { TCTTGGTCAGTCCTATGCGGATA } \\
(219-241)\end{array}$ & $\begin{array}{l}\text { CGGATCCTGAGTCACAGACACA } \\
(296-274)\end{array}$ & $\begin{array}{c}\text { 6-FAM-AGATGT } \\
\text { CTGGAAGCCAGA } \\
\text { ACCATGCC-6-TA } \\
\text { MRA }(243-268)\end{array}$ \\
\hline $\mathrm{h} T I M P 1$ & BC 000866 & $\begin{array}{l}\text { GACGGCCTTCTGCAATTCC } \\
(241-259)\end{array}$ & $\begin{array}{l}\text { GTATAAGGTGGTCTGGTTGACTTCTG } \\
(319-294)\end{array}$ & - \\
\hline $\mathrm{h} T I M P 2$ & $\mathrm{BC} 052605$ & $\begin{array}{l}\text { CCCTCCTCGGCAGTGTGT } \\
(556-573)\end{array}$ & $\begin{array}{l}\text { CGGCCTTTCCTGCAATGA } \\
(628-611)\end{array}$ & - \\
\hline $\mathrm{h} G A P D H$ & BT 006893 & $\begin{array}{l}\text { GGAGTCAACGGATTTGGTCGTA } \\
\qquad(19-40)\end{array}$ & $\begin{array}{l}\text { CAACAATATCCACTTTACCAGAGTTA } \\
(94-69)\end{array}$ & \\
\hline & & ABI ref\# & & \\
\hline $\mathrm{h}$ Fibl & NM_001996 & Hs00972609 & & \\
\hline $\mathrm{h} F i b 2$ & NM_001004019 & Hs00157482 & & \\
\hline $\mathrm{h} F i b 3$ & NM_001039348 & Hs00244575 & & \\
\hline $\mathrm{h} F i b 4$ & NM_016938 & Hs00973815 & & \\
\hline $\mathrm{h}$ Fib5 & NM_006329 & Hs00197064 & & \\
\hline $\mathrm{h} F i b 7$ & NM_001128165 & Hs00402230 & & \\
\hline $\mathrm{h} B M P 1$ & NM_001199 & Hs00241807 & & \\
\hline $\mathrm{h} M M P 7$ & NM_002423 & Hs01042796 & & - \\
\hline
\end{tabular}

single amplicon. Levels of mRNA were determined using the ddCt method (Applied Biosystems) and expressed relative to an external calibrator present on each plate. Primers used in this study are listed in Table 2.

\section{Immunoblot analysis}

Frozen ovarian tissues were pulverized with a liquid nitrogen-chilled mortar and pestle. Tissue powder was then homogenized in potassium phosphate buffer (16 $\mathrm{mM}$ potassium phosphate, $\mathrm{pH} 7.8,0.12 \mathrm{M} \mathrm{NaCl}$, $1 \mathrm{mM}$ ethylenediaminetetraacetic acid) containing a protease inhibitor cocktail (Complete Mini, product number 11836153001, Roche Diagnostics, Penzberg, Germany), and then centrifuged at $10,000 \mathrm{~g}$ for $10 \mathrm{~min}$. The supernatant (S1) was removed, and the previous homogenization step was repeated after resuspending the remaining tissue pellet in potassium phosphate buffer. After removal of the second supernatant (S2), the remaining tissue pellet was suspended in urea buffer ( 6.0
M urea in potassium phosphate buffer), homogenized, and extracted overnight at $4^{\circ} \mathrm{C}$. Thereafter, the samples were centrifuged (13,000 $\mathrm{g}$ for $30 \mathrm{~min}$ ), and the supernatant (S3) was removed. Protein concentrations were determined using a bicinchoninic acid protein assay (Pierce, Rockford, IL, USA) and standard curves of BSA in appropriate buffers. Total protein $(30 \mu \mathrm{g} / \mathrm{lane})$ was applied to 4 to $20 \%$ Criterion gradient polyacrylamide gels (Bio-Rad, Hercules, CA, USA), separated by electrophoresis, and transferred to nitrocellulose membranes overnight at $4^{\circ} \mathrm{C}$. To ensure equal protein loading, identical gels were run side-by-side for Coomassie brilliant blue staining. Nitrocellulose membranes were placed in blocking buffer (10 mM Tris-HCl, $\mathrm{pH} 7.5,0.15 \mathrm{M} \mathrm{NaCl}, 0.1 \%$ Tween 20 , $2 \%$ nonfat powdered milk) for $1 \mathrm{~h}$ at $37^{\circ} \mathrm{C}$ and incubated with primary antibody (1:1000 dilution) for $1 \mathrm{~h}$ at $37^{\circ} \mathrm{C}$. Primary antibodies were human fibulin 5 antibody (monoclonal mouse IgG1 Clone \# 293904 derived from $\mathrm{Gln}^{24}-\mathrm{Phe}^{448}$ of recombinant human Fibulin 5 (epitope unknown, R\&D Systems, Minneapolis, MN, USA) and a 
polyclonal antibody raised against full length rat FBLN5 that recognizes the human protein [23] (a kind gift from Dr. Elaine Davis, McGill University). Membranes were then washed with Tris-buffered saline solution (TBST) (10 mM Tris- $\mathrm{HCl}, \mathrm{pH} 7.5,0.15 \mathrm{M} \mathrm{NaCl}$, and $0.1 \%$ Tween 20 ) for $3 \mathrm{~min} \times 5$. Thereafter, the blot was incubated with goat-anti-rabbit horseradish peroxidase conjugate (BioRad, 1:10000 dilution) at room temperature for $1 \mathrm{~h}$. The membrane wash protocol was repeated, followed by incubation with Western Lighting Chemiluminescence Reagent Plus (Perkin-Elmer, Boston, MA, USA) for 2 min. Chemiluminescence images were obtained on a Fuji LAS 3000 image analysis system (Fujifilm Life Science, Stamford, CT, USA).

\section{Gelatin zymography}

Frozen ovarian tissues were pulverized with a liquid nitrogen-chilled mortar and pestle. Tissues were then homogenized in Tris buffer $(10 \mathrm{mM}$ Tris- $\mathrm{HCl}, \mathrm{pH}$ 7.4, $150 \mathrm{mM} \mathrm{NaCl}, 10 \mathrm{mM} \mathrm{CaCl}, 0.1 \%$ Triton X-100). Homogenates were centrifuged at $10,000 \mathrm{~g}$ for $15 \mathrm{~min}$ at $4^{\circ}$ C. The supernatant was used for determination of protease activity. Protein concentrations were determined using bicinchoninic acid protein assay and standard curves of BSA in appropriate buffers. Samples ( $5 \mu \mathrm{g}$ per lane) were applied to gelatin polyacrylamide minigels (Invitrogen, Carlsbad, CA, USA) (10\%) in standard SDS loading buffer containing $0.1 \%$ SDS with no -mercaptoethanol; the samples were not boiled before loading. Gels were run at room temperature at $125 \mathrm{~V}$. After electrophoresis, gels were soaked in renaturing buffer $(2.7 \%$ [v/v] Triton X-100 in distilled water) in a shaker for $30 \mathrm{~min}$ with one change after $30 \mathrm{~min}$ to remove SDS. Next, gels were soaked in developing buffer (50 mM Tris, $200 \mathrm{mM} \mathrm{NaCl}, 5 \mathrm{mM}$ $\mathrm{CaCl}_{2}, 0.02 \%$ Brij 35, pH 7.5) overnight at $37^{\circ} \mathrm{C}$ and then stained with Coomassie brilliant blue-R 250 in $40 \%$ methanol and 10\% acetic acid followed by washing with distilled water for $1 \mathrm{~min}$. Clear zones of lysis against a dark background indicated enzyme activity. Areas of lysis were quantified using the Fuji LAS 3000 image analysis system.

\section{Cell adhesion assay}

Three distinct epithelial ovarian cancer cell lines were used. All were developed by and provided by one of the authors (A.G.). The cell lines were developed from metastatic tumor ascites obtained at the time of cytoreductive surgery for advanced stage epithelial ovarian cancer from patients treated at the University of Texas Southwestern Medical Center (Table 1). Cells were cultured in ACL4 media (RPMI 1640 with insulin [0.02 $\mathrm{mg} / \mathrm{ml}]$, transferrin $[0.01 \mathrm{mg} / \mathrm{ml}]$, sodium selenite [25 $\mathrm{nM}]$, hydrocortisone [50 $\mathrm{nM}]$, HEPES [10 $\mathrm{mM}]$, epidermal growth factor $\left[\begin{array}{ll}1 & \mathrm{ng} / \mathrm{ml}\end{array}\right]$, ethanolamine
[0.01 $\mathrm{mM}]$, O-phosphorylethanolamine $[0.01 \mathrm{mM}]$, triiodothyronine $[0.1 \mathrm{nM}]$, bovine serum albumin $[2 \mathrm{mg} /$ $\mathrm{mL}]$, sodium pyruvate $[0.5 \mathrm{mM}]$ and L-glutamine [2.05 $\mathrm{mM}]$ ) in a $37 \mathrm{C}$ humidified incubator with $5 \% \mathrm{CO}_{2}$. For the adhesion assay, a 48-Well CytoSelect Cell Adhesion Assay was used (Cell Biolabs, Inc., Catalog \#CBA-070, San Diego, CA, USA). This kit consists of a 48-well cell culture plate pre-coated with six extracellular matrix proteins (fibronectin, collagen I, collagen IV, laminin I, fibrinogen and BSA). Half of the wells were additionally coated with $500 \mathrm{ng}$ of recombinant human fibulin 5 (R\&D Systems \#3095-FB, Minneapolis, MN, USA) at a concentration of $10 \mu \mathrm{g} / \mathrm{mL}$ in PBS, and half were coated with $500 \mathrm{ng}$ of BSA at a concentration of $10 \mu \mathrm{g} /$ $\mathrm{mL}$ in PBS. These plates were allowed to air-dry under a sterile hood. Thereafter cells were plated according to the manufacturer's protocol using a cell suspension concentration of $1 \times 10^{6}$ cells $/ \mathrm{mL}$. Cells were allowed to incubate for 2 hours prior to continuing the protocol.

\section{Proteolytic cleavage assays}

Recombinant human fibulin 5 (R\&D Systems \#3095-FB, Minneapolis, MN, USA) was incubated with various proteases. All reactions were performed in a basic buffer (50 mM Tris-HCl, $\mathrm{pH} 7.4,150 \mathrm{mM} \mathrm{NaCl}$, $5 \mathrm{mM} \mathrm{CaCl}_{2}, 0.1 \%$ TX-100, 0.01\% brij L23). Enzymes were added to rhFib5 in the following molar ratios: $1: 1.4$, trypsin; $1: 3.2$, elastase, $1: 8$; thrombin, $1: 17$; MMP9, 1:28; and 1:8 - 1:36, MMP-7. For the MMP9 assay, proMMP-9 (RayBiotech \#228-11326) was incubated with 4-aminophenylmercuric acetate (APMA) at $37 \mathrm{C} \times$ 60 minutes to convert to active MMP-9. Thereafter, 10 ng of activated MMP-9 was added to $200 \mathrm{ng}$ rhFib5 in a total of $20 \mu \mathrm{L}$ of buffer for each time point $(0,2,4,6,12$ and 24 hours). Samples were boiled prior to loading on a 4 to $20 \%$ Criterion gradient polyacrylamide gels (BioRad, Hercules, CA, USA). For thrombin, $0.01 \mathrm{U}$ thrombin (Sigma T6884) was incubated with $200 \mathrm{ng}$ rhFib5 in a total of $20 \mu \mathrm{L}$ of buffer for each time point $(0,2,4,6,12$ and 24 hours). For MMP-2, 50 ng MMP-2 (PeproTech Cat. \#420-02) was incubated with $200 \mathrm{ng}$ rhFib5 in a total of $20 \mu \mathrm{L}$ of buffer for each time point $(0,2,2.5,3,3.5$ and 4 hours). For trypsin, 50 ng trypsin (Sigma T4049) was incubated with $200 \mathrm{ng}$ rhFib5 in a total of $20 \mu \mathrm{L}$ of buffer for each time point (0, 2, 2.5, 3, 3.5 and 4 hours). Elastase assays were conducted with $25 \mathrm{ng}$ of porcine pancreatic elastase (Sigma 45124) incubated with $200 \mathrm{ng}$ rhFib5 in a total of $20 \mu \mathrm{L}$ of buffer for each time point $(0,1,12,24$, 36,48 and 60 minutes). For the MMP-7 assay, 50 or 2.5 ng MMP-7 was incubated with $200 \mathrm{ng}$ rhFib5 in a total of $20 \mu \mathrm{L}$ of buffer for each time point $(0,10,20,30,40$, 50 and 60 seconds). Samples were boiled, loaded onto 4 to $20 \%$ polyacrylamide gels, separated by electrophoresis, transferred to PVDF membrane and immunoblotted as previously described. 


\section{Mass spectrometry identification of degraded FBLN5}

Protein gel pieces were digested overnight with elastase (Promega) following reduction and alkylation with DTT and iodoacetamide (Sigma-Aldrich). Then, samples underwent solid-phase extraction cleanup with Oasis HLB plates (Waters) and the resulting samples were analyzed by LC/MS/MS, using an Orbitrap Fusion Lumos mass spectrometer (Thermo Electron) coupled to an Ultimate 3000 RSLC-Nano liquid chromatography systems (Dionex). Samples were injected onto a $75 \mu \mathrm{m}$ i.d., 50-cm long EasySpray column (Thermo), and eluted with a gradient from $1-28 \%$ buffer B over $40 \mathrm{~min}$. Buffer A contained $2 \%(\mathrm{v} / \mathrm{v})$ acetonitrile $(\mathrm{CAN})$ and $0.1 \%$ formic acid in water, and buffer B contained $80 \%(\mathrm{v} / \mathrm{v})$ $\mathrm{ACN}, 10 \%(\mathrm{v} / \mathrm{v})$ trifluoroethanol, and $0.1 \%$ formic acid in water. The mass spectrometer operated in positive ion mode with a source voltage of $2.4 \mathrm{kV}$ and an ion transfer tube temperature of $275^{\circ} \mathrm{C}$. MS scans were acquired at 120,000 resolution in the Orbitrap and up to $10 \mathrm{MS} / \mathrm{MS}$ spectra were obtained in the ion trap for each full spectrum acquired using higher-energy collisional dissociation (HCD) for ions with charges 2-7. Dynamic exclusion was set for $25 \mathrm{~s}$ after an ion was selected for fragmentation.

Raw MS data files were converted to a peak list format and analyzed using the central proteomics facilities pipeline (CPFP), version 2.0.3 [52, 53]. Peptide identification was performed using a non-specific search with the open MS search algorithm (OMSSA) [54] against the appropriate protein database from Uniprot, with common contaminants and reversed decoy sequences appended [55]. Fragment and precursor tolerances of 20 ppm and 0.6 Da were specified. Carbamidomethylation of Cys was set as a fixed modification and oxidation of Met was set as a variable modification. At least two peptide spectral matches were required for a peptide to be considered confidently identified.

\section{Immunohistochemistry}

Formalin-fixed paraffin-embedded tissues were sectioned at 4 microns and mounted on adhesive slides, along with multi-tumor sandwich block sections containing over 50 different normal and tumor tissues for external positive and negative controls [56]. After drying $\times 1 \mathrm{~min}$ in an $1100 \mathrm{~W}$ microwave oven, slides were transferred to a $65^{\circ} \mathrm{C}$ oven and dried for an additional $20 \mathrm{~min}$. Thereafter, slides were deparaffinized in xylene and rehydrated in graded alcohols to distilled water. Endogenous peroxidase activity was quenched for $10 \mathrm{~min}$ at room temperature using $0.3 \% \mathrm{H}_{2} \mathrm{O}_{2}$ with $0.1 \%$ sodium azide. Primary antibodies were polyclonal fibulin 5 antibody [23] (1:500) in which antigen retrieval was conducted in $1 \mathrm{mM}$ EDTA, pH $8.5 \times 30 \mathrm{~min}$ in a household vegetable steamer, followed by $10 \mathrm{~min}$ cool-down time.
For CD68, slides were placed in 0.25 Tris base buffer, $\mathrm{pH} 9.0$, in a pressure cooker. After rinsing in phosphate buffered saline (PBS) buffer, primary antibody incubation was performed for $50 \mathrm{~min}$ in a $25^{\circ} \mathrm{C}$ incubation oven, using gentle orbital rotation. Following another rinse in PBS, incubation with anti-rabbit or anti-mouse horseradish peroxidase-conjugated polymer (PowerVision Poly-HRP anti-rabbit IgG, Leica Biosystems, Buffalo Grove, IL, USA) was performed for 45 minutes at $25^{\circ} \mathrm{C}$. Finally, slides were immersed for 8 minutes in $25^{\circ} \mathrm{C}$ diaminobenzidine (DAB) (Invitrogen, Carlsbad, CA), enhanced with $0.5 \%$ copper sulfate in PBS $\times 3 \mathrm{~min}$, counterstained in hematoxylin, dehydrated in graded alcohols, cleared in xylene, and coverslipped. Negative controls were comprised of all treatments but without primary antibody.

\section{Statistical Analysis}

Sample size for ovarian EOC immunoblotting was determined using pilot data of 12 benign and 4 ovarian tumors indicating that 10 tissues in each group were required for statistical significance at $P<0.05$ with $80 \%$ power. Data are presented as mean $\pm \mathrm{SD}$ for data derived from a single experiment and as mean \pm SEM for data combined from two or more experiments. Student's $t$ test with Bonferroni correction for multiple comparisons was used as appropriate or Fisher's exact as noted.

\section{Author contributions}

DM conducted the experiments, enrolled patients, analyzed data, and generated figures; HKA conducted gene amplification and designed primers and optimized antibody dilutions; AFG provided the cell lines and optimized cell growth conditions; PWK mentored DM throughout the project regarding gene amplification and immunoblotting techniques, JT contributed to design and implementation of MMP7 experiments, HY contributed to the discussion and writing of the manuscript; JSL and RAW conceived the experimental plan, monitored all data, and wrote the manuscript.

\section{CONFLICTS OF INTEREST}

The authors have nothing to disclose.

\section{FINANCIAL SUPPORT}

This work was supported by NIH AG028048.

\section{REFERENCES}

1. Siegel R, Naishadham D, Jemal A. Cancer statistics, 2012. CA Cancer J Clin. 2012; 62:10-29. https://doi.org/10.3322/ caac. 20138. 
2. Chi DS, Sabbatini P. Advanced ovarian cancer. Curr Treat Options Oncol. 2000; 1:139-46.

3. Kobayashi N, Kostka G, Garbe JH, Keene DR, Bachinger HP, Hanisch FG, Markova D, Tsuda T, Timpl R, Chu ML, Sasaki T. A comparative analysis of the fibulin protein family. Biochemical characterization, binding interactions, and tissue localization. J Biol Chem. 2007; 282:11805-16. https://doi.org/10.1074/jbc.M611029200.

4. Moller HD, Ralfkjaer U, Cremers N, Frankel M, Pedersen RT, Klingelhofer J, Yanagisawa H, Grigorian M, Guldberg P, Sleeman J, Lukanidin E, Ambartsumian N. Role of fibulin-5 in metastatic organ colonization. Mol Cancer Res. 2011; 9:553-63. https://doi.org/10.1158/1541-7786. MCR-11-0093.

5. Yue W, Sun Q, Landreneau R, Wu C, Siegfried JM, Yu J, Zhang L. Fibulin-5 suppresses lung cancer invasion by inhibiting matrix metalloproteinase-7 expression. Cancer Res. 2009; 69:6339-46. https://doi.org/10.1158/0008-5472. CAN-09-0398.

6. Schluterman MK, Chapman SL, Korpanty G, Ozumi K, Fukai T, Yanagisawa H, Brekken RA. Loss of fibulin-5 binding to betal integrins inhibits tumor growth by increasing the level of ROS. Dis Model Mech. 2010; 3:333-42. https://doi.org/10.1242/dmm.003707.

7. Hu Z, Ai Q, Xu H, Ma X, Li HZ, Shi TP, Wang C, Gong DJ, Zhang X. Fibulin-5 is down-regulated in urothelial carcinoma of bladder and inhibits growth and invasion of human bladder cancer cell line 5637. Urol Oncol. 2011; 29:430-5. https://doi.org/10.1016/j.urolonc.2009.06.004.

8. Wlazlinski A, Engers R, Hoffmann MJ, Hader C, Jung V, Muller M, Schulz WA. Downregulation of several fibulin genes in prostate cancer. Prostate. 2007; 67:1770-80. https://doi.org/10.1002/pros.20667.

9. Lee YH, Albig AR, Regner M, Schiemann BJ, Schiemann WP. Fibulin-5 initiates epithelial-mesenchymal transition (EMT) and enhances EMT induced by TGF-beta in mammary epithelial cells via a MMP-dependent mechanism. Carcinogenesis. 2008; 29:2243-51. https://doi. org/10.1093/carcin/bgn199.

10. Timpl R, Sasaki T, Kostka G, Chu ML. Fibulins: a versatile family of extracellular matrix proteins. Nat Rev Mol Cell Biol. 2003; 4:479-89. https://doi.org/10.1038/nrm1130.

11. Hirai M, Ohbayashi T, Horiguchi M, Okawa K, Hagiwara A, Chien KR, Kita T, Nakamura T. Fibulin-5/DANCE has an elastogenic organizer activity that is abrogated by proteolytic cleavage in vivo. J Cell Biol. 2007; 176:1061-71. https://doi.org/10.1083/jcb.200611026.

12. Spencer JA, Hacker SL, Davis EC, Mecham RP, Knutsen RH, Li DY, Gerard RD, Richardson JA, Olson EN, Yanagisawa H. Altered vascular remodeling in fibulin-5deficient mice reveals a role of fibulin-5 in smooth muscle cell proliferation and migration. Proc Natl Acad Sci USA. 2005; 102:2946-51.

13. Albig AR, Schiemann WP. Fibulin-5 antagonizes vascular endothelial growth factor (VEGF) signaling and ang iogenic sprouting by endothelial cells. DNA Cell Biol. 2004; 23:367-79.

14. Budatha M, Roshanravan S, Zheng Q, Weislander C, Chapman SL, Davis EC, Starcher B, Word RA, Yanagisawa H. Extracellular matrix proteases contribute to progression of pelvic organ prolapse in mice and humans. J Clin Invest. 2011; 121:2048-59. https://doi.org/10.1172/JCI45636.

15. Kamat AA, Fletcher M, Gruman LM, Mueller P, Lopez A, Landen CN Jr, Han L, Gershenson DM, Sood AK. The clinical relevance of stromal matrix metalloproteinase expression in ovarian cancer. Clin Cancer Res. 2006; 12:1707-14. https:// doi.org/10.1158/1078-0432.CCR-05-2338.

16. Lomas AC, Mellody KT, Freeman LJ, Bax DV, Shuttleworth CA, Kielty CM. Fibulin-5 binds human smooth-muscle cells through alpha5beta1 and alpha4beta1 integrins, but does not support receptor activation. Biochem J. 2007; 405:417-28. https://doi.org/10.1042/BJ20070400.

17. Preis M, Cohen T, Sarnatzki Y, Ben Yosef Y, Schneiderman J, Gluzman Z, Koren B, Lewis BS, Shaul Y, Flugelman MY. Effects of fibulin-5 on attachment, adhesion, and proliferation of primary human endothelial cells. Biochem Biophys Res Commun. 2006; 348:1024-33. https://doi. org/10.1016/j.bbrc.2006.07.156.

18. Williamson MR, Shuttleworth A, Canfield AE, Black RA, Kielty CM. The role of endothelial cell attachment to elastic fibre molecules in the enhancement of monolayer formation and retention, and the inhibition of smooth muscle cell recruitment. Biomaterials. 2007; 28:5307-18. https://doi. org/10.1016/j.biomaterials.2007.08.019.

19. Kapustin A, Stepanova V, Aniol N, Cines DB, Poliakov A, Yarovoi S, Lebedeva T, Wait R, Ryzhakov G, Parfyonova Y, Gursky Y, Yanagisawa H, Minashkin M, et al. Fibulin-5 binds urokinase-type plasminogen activator and mediates urokinasestimulated beta1-integrin-dependent cell migration. Biochem J. 2012; 443:491-503. https://doi.org/10.1042/BJ20110348.

20. Schiemann WP, Blobe GC, Kalume DE, Pandey A, Lodish HF. Context-specific effects of fibulin-5 (DANCE/EVEC) on cell proliferation, motility, and invasion. Fibulin-5 is induced by transforming growth factor-beta and affects protein kinase cascades. J Biol Chem. 2002; 277:27367-77. https://doi.org/10.1074/jbc.M200148200.

21. Tu K, Dou C, Zheng X, Li C, Yang W, Yao Y, Liu Q. Fibulin-5 inhibits hepatocellular carcinoma cell migration and invasion by down-regulating matrix metalloproteinase-7 expression. BMC Cancer. 2014; 14:938-46.

22. Li F, Xu H, Zeng Y, Yin ZQ. Overexpression of fibulin-5 in retinal pigment epithelial cells inhibits cell proliferation and migration and downregulates VEGF, CXCR4, and TGFB1 expression in cocultured choroidal endothelial cells. Curr Eye Res. 2012; 37:540-8. https://doi.org/10.3109/0271368 3.2012 .665561 .

23. Hu Q, Loeys BL, Coucke PJ, De Paepe A, Mecham RP, Choi J, Davis EC, Urban Z. Fibulin-5 mutations: mechanisms of impaired elastic fiber formation in recessive cutis laxa. Hum Mol Genet. 2006; 15:3379-86. 
24. Thu KL, Papari-Zareei M, Stastny V, Song K, Peyton M, Martinez VD, Zhang YA, Castro IB, Varella-Garcia M, Liang H, Xing C, Kittler R, Milchgrub S, et al. A comprehensively characterized cell line panel highly representative of clinical ovarian high-grade serous carcinomas. Oncotarget. 2017; 8:50489-99. https://doi. org/10.18632/oncotarget.9929.

25. Nadarajah D, Atkinson MA, Huebner P, Starcher B. Enzyme kinetics and characterization of mouse pancreatic elastase. Connect Tissue Res. 2008; 49:409-15. https://doi. org/10.1080/03008200802272379.

26. Werb Z, Banda MJ, McKerrow JH, Sandhaus RA. Elastases and elastin degradation. J Invest Dermatol. 1982; 79:154s-9s.

27. Sepper R, Konttinen YT, Ingman T, Sorsa T. Presence, activities, and molecular forms of cathepsin G, elastase, alpha 1-antitrypsin, and alpha 1-antichymotrypsin in bronchiectasis. J Clin Immunol. 1995; 15:27-34.

28. Shiomi T, Okada Y. MT1-MMP and MMP-7 in invasion and metastasis of human cancers. Cancer Metastasis Rev. 2003; 22:145-52.

29. Wang FQ, So J, Reierstad S, Fishman DA. Matrilysin (MMP-7) promotes invasion of ovarian cancer cells by activation of progelatinase. Int J Cancer. 2005; 114:19-31. https://doi.org/10.1002/ijc.20697.

30. Zeng ZS, Shu WP, Cohen AM, Guillem JG. Matrix metalloproteinase-7 expression in colorectal cancer liver metastases: evidence for involvement of MMP-7 activation in human cancer metastases. Clin Cancer Res. 2002; 8:144-8.

31. Heo JH, Song JY, Jeong JY, Kim G, Kim TH, Kang H, Kwon AY, An HJ. Fibulin-5 is a tumour suppressor inhibiting cell migration and invasion in ovarian cancer. J Clin Pathol. 2016; 69:109-16. https://doi.org/10.1136/ jclinpath-2015-203129.

32. Huang S, Van Arsdall M, Tedjarati S, McCarty M, Wu W, Langley R, Fidler IJ. Contributions of stromal metalloproteinase-9 to angiogenesis and growth of human ovarian carcinoma in mice. J Natl Cancer Inst. 2002; 94:1134-42.

33. Shibata K, Kikkawa F, Nawa A, Tamakoshi K, Suganuma $\mathrm{N}$, Tomoda Y. Increased Matrix Metalloproteinase-9 Activity in Human Ovarian Cancer Cells Cultured with Conditioned Medium from Human Peritoneal Tissue. Clin Exp Metastasis. 1997; 15:612-9.

34. Sillanpaa S, Anttila M, Voutilainen K, Ropponen K, Turpeenniemi-Hujanen T, Puistola U, Tammi R, Tammi M, Sironen R, Saarikoski S, Kosma VM. Prognostic significance of matrix metalloproteinase-9 (MMP-9) in epithelial ovarian cancer. Gynecol Oncol. 2007; 104:296-303. https://doi.org/10.1016/j.ygyno.2006.09.004.

35. Yang SW, Chanda D, Cody JJ, Rivera AA, Waehler R, Siegal GP, Douglas JT, Ponnazhagan S. Conditionally replicating adenovirus expressing TIMP2 increases survival in a mouse model of disseminated ovarian cancer. PLoS One. 2011; 6:e25131. https://doi.org/10.1371/journal.pone.0025131.
36. Vierkotten S, Muether PS, Fauser S. Overexpression of HTRA1 leads to ultrastructural changes in the elastic layer of Bruch's membrane via cleavage of extracellular matrix components. PLoS One. 2011; 6:e22959. https://doi. org/10.1371/journal.pone.0022959.

37. Djokic J, Fagotto-Kaufmann C, Bartels R, Nelea V, Reinhardt DP. Fibulin-3, -4 , and -5 are highly susceptible to proteolysis, interact with cells and heparin, and form multimers. J Biol Chem. 2013; 288:22821-35. https://doi. org/10.1074/jbc.M112.439158.

38. Nakamura T, Lozano PR, Ikeda Y, Iwanaga Y, Hinek A, Minamisawa S, Cheng CF, Kobuke K, Dalton N, Takada Y, Tashiro K, Ross J Jr, Honjo T, Chien KR. Fibulin-5/ DANCE is essential for elastogenesis in vivo. Nature. 2002; 415:171-5.

39. Buczek-Thomas JA, Chen N, Hasan T. Integrin-mediated adhesion and signalling in ovarian cancer cells. Cell Signal. 1998; 10:55-63.

40. Ahmed N, Pansino F, Clyde R, Murthi P, Quinn MA, Rice GE, Agrez MV, Mok S, Baker MS. Overexpression of alpha(v) beta6 integrin in serous epithelial ovarian cancer regulates extracellular matrix degradation via the plasminogen activation cascade. Carcinogenesis. 2002; 23:237-44.

41. Heinzelmann-Schwarz VA, Gardiner-Garden M, Henshall SM, Scurry J, Scolyer RA, Davies MJ, Heinzelmann M, Kalish LH, Bali A, Kench JG, Edwards LS, Vanden Bergh PM, Hacker NF, et al. Overexpression of the cell adhesion molecules DDR1, Claudin 3, and Ep-CAM in metaplastic ovarian epithelium and ovarian cancer. Clin Cancer Res. 2004; 10:4427-36. https:// doi.org/10.1158/1078-0432.CCR-04-0073.

42. Laval S, Butler R, Shelling AN, Hanby AM, Poulsom R, Ganesan TS. Isolation and characterization of an epithelialspecific receptor tyrosine kinase from an ovarian cancer cell line. Cell Growth Differ. 1994; 5:1173-83.

43. Budatha M, Silva S, Montoya TI, Suzuki A, Shah-Simpson S, Wieslander CK, Yanagisawa M, Word RA, Yanagisawa H. Dysregulation of protease and protease inhibitors in a mouse model of human pelvic organ prolapse. PLoS One. 2013; 8:e56376. https://doi.org/10.1371/journal.pone.0056376.

44. Condeelis J, Pollard JW. Macrophages: obligate partners for tumor cell migration, invasion, and metastasis. Cell. 2006; 124:263-6. https://doi.org/10.1016/j.cell.2006.01.007.

45. Lu P, Weaver VM, Werb Z. The extracellular matrix: a dynamic niche in cancer progression. J Cell Biol. 2012; 196:395-406. https://doi.org/10.1083/jcb.201102147.

46. Brun JL, Cortez A, Commo F, Uzan S, Rouzier R, Darai E. Serous and mucinous ovarian tumors express different profiles of MMP-2, -7, -9, MT1-MMP, and TIMP-1 and -2. Int J Oncol. 2008; 33:1239-46.

47. Gershtein ES, Levkina NV, Digayeva MA, Laktionov KP, Tereshkina IV, Kushlinsky NE. Matrix metalloproteinases 2, 7, and 9 and tissue inhibitor of metalloproteinases- 1 in tumors and serum of patients with ovarian neoplasms. Bull Exp Biol Med. 2010; 149:628-31. 
48. Hagemann T, Robinson SC, Schulz M, Trumper L, Balkwill FR, Binder C. Enhanced invasiveness of breast cancer cell lines upon co-cultivation with macrophages is due to TNFalpha dependent up-regulation of matrix metalloproteases. Carcinogenesis. 2004; 25:1543-9. https://doi.org/10.1093/ carcin/bgh146.

49. Lindqvist A, Manders D, Word RA. The impact of reference gene selection in quantification of gene expression levels in guinea pig cervical tissues and cells. BMC Res Notes. 2013; 6:34-43.

50. Havelock JC, Keller P, Muleba N, Mayhew BA, Casey BM, Rainey WE, Word RA. Human myometrial gene expression before and during parturition. Biol Reprod. 2005; 72:70719. https://doi.org/10.1095/biolreprod.104.032979.

51. Montoya TI, Maldonado PA, Acevedo JF, Word RA. Effect of vaginal or systemic estrogen on dynamics of collagen assembly in the rat vaginal wall. Biol Reprod. 2015; 92: 43. https://doi.org/10.1095/biolreprod.114.118638.

52. Trudgian DC, Mirzaei H. Cloud CPFP: a shotgun proteomics data analysis pipeline using cloud and high performance computing. J Proteome Res. 2012; 11:6282-90. https://doi.org/10.1021/pr300694b.

53. Trudgian DC, Thomas B, McGowan SJ, Kessler BM, Salek M, Acuto O. CPFP: a central proteomics facilities pipeline. Bioinformatics. 2010; 26:1131-2. https://doi.org/10.1093/ bioinformatics/btq081.

54. Geer LY, Markey SP, Kowalak JA, Wagner L, Xu M, Maynard DM, Yang X, Shi W, Bryant SH. Open mass spectrometry search algorithm. J Proteome Res. 2004; 3:958-64. https://doi.org/10.1021/pr0499491.

55. Elias JE, Gygi SP. Target-decoy search strategy for increased confidence in large-scale protein identifications by mass spectrometry. Nat Methods. 2007; 4:207-14. https://doi.org/10.1038/nmeth1019.

56. Miller RT, Groothuis CL. Multitumor "sausage" blocks in immunohistochemistry. Simplified method of preparation, practical uses, and roles in quality assurance. Am J Clin Pathol. 1991; 96:228-32. 